\title{
Geoquímica de piroclastos intemperizados da Caldeira Vulcânica de Poços de Caldas, Minas Gerais
}

\author{
Geochemistry of weathered pyroclastic deposits from
}

the Poços de Caldas Volcanic Caldera, Minas Gerais

\author{
André Luis Reis Bacha' (D), Diego de Souza Sardinha' ${ }^{1}$ (D), Letícia Hirata Godoy' ${ }^{1}$ (D), Matheus Fernando Ancelmi ${ }^{1}$ (D) \\ ${ }^{1}$ Universidade Federal de Alfenas - UNIFAL, Instituto de Ciência e Tecnologia, Rodovia José Aurélio Vilela, 11999, \\ BR 267, Km 533, Cidade Universitária, CEP 37715-400, Poços de Caldas, MG, BR (alrbacha@gmail.com; \\ diego.sardinha@unifal-mg.edu.br; leticiahirata@gmail.com; matheus.ancelmi@unifal-mg.edu.br)
}

Recebido em 6 de agosto de 2019; aceito em 18 de agosto de 2020

\begin{abstract}
Resumo
A caldeira vulcânica de Poços de Caldas é um dos maiores complexos magmáticos alcalinos circulares do mundo. Em razão da escassez de trabalhos sobre piroclastos que afloram nessa região, o presente estudo surgiu com o objetivo de caracterizar a geoquímica dos piroclastos intemperizados. Quatro afloramentos representativos foram selecionados, sendo classificados os tipos de depósitos e coletadas amostras totais (matriz + clasto) para a análise dos principais óxidos, elementos traços e terras raras. Os quatro pontos estudados (P1, P2, P3 e P4) apresentam litofácies lapilli tufo sem estrutura, tufo brecha indiferenciada sem estrutura e lapilli tufo grosseiro. As amostras possuem altas concentrações de $\mathrm{Al}_{2} \mathrm{O}_{3}, \mathrm{Fe}_{2} \mathrm{O}_{3}, \mathrm{TiO}_{2}$ e baixas de $\mathrm{SiO}_{2}, \mathrm{~K}_{2} \mathrm{O}, \mathrm{Na}_{2} \mathrm{O}, \mathrm{CaO}$ e $\mathrm{MgO}$, com trend avançado de intemperismo. As concentrações de elementos traços são similares às rochas da Caldeira Vulcânica, com altas concentrações de Ni, Cr, Co e V. Observou-se tendência de enriquecimento em High Field Strength Elements (HFSE) e empobrecimento em Large Ion Lithophile Elements (LILE), à exceção do Ba, cujas altas concentrações podem estar relacionadas com as baixas concentrações de $\mathrm{K}_{2} \mathrm{O}$. Os elementos terras raras (ETR) apresentam padrão de fracionamento contínuo caracterizado pelo empobrecimento de elementos terras raras leves (ETRL) aos elementos terras raras pesados (ETRP) e pela ausência de anomalia de $\mathrm{Eu}\left(\mathrm{Eu} / \mathrm{Eu}^{*}=0,98 \pm 0,02\right)$. Em comparação aos ETR das rochas da Caldeira Vulcânica, há maior empobrecimento em $\operatorname{ETRP}\left(\mathrm{Gd} / \mathrm{Lu}_{\mathrm{nc}}=6,8 \pm 3\right)$, provavelmente relacionado ao intemperismo dos perfis estudados. Porém, os ETR também apresentam padrões de fracionamento diferenciados em relação aos saprólitos, solos e bauxitas, o que lhes confere características não pedogênicas, indicando que esses depósitos ainda preservam a assinatura geoquímica do magma primordial, corroborando com o modelo evolutivo de caldeira vulcânica para Poços de Caldas.
\end{abstract}

Palavras-chave: Complexo alcalino; Depósitos piroclásticos; Tufos vulcânicos intemperizados; Modelo evolutivo.

\begin{abstract}
The Poços de Caldas Volcanic Caldera is considered one of the largest circular alkaline magmatic complexes of the world. Due to the lack of studies about the pyroclasts deposits that crop out in the region, this study aimed at the geochemical characterization of the weathered pyroclasts. Four representative outcrops were selected in order to classify the types of deposits and to collect total samples (matrix + clast) for the chemical analysis of the main oxides, trace and rare earth elements (REE). Four points selected for the study (P1, P2, P3, and P4) exhibit structureless lapilli tuff, structureless undifferentiated tuffitic breccia, and coarse lapilli tuff. The samples present high $\mathrm{Al}_{2} \mathrm{O}_{3}, \mathrm{Fe}_{2} \mathrm{O}_{3}, \mathrm{TiO}_{2}$ and low $\mathrm{SiO}_{2}, \mathrm{~K}_{2} \mathrm{O}, \mathrm{Na}_{2} \mathrm{O}, \mathrm{CaO}$, and $\mathrm{MgO}$ concentrations, revealing an advanced weathering trend. Trace element concentrations are similar to rocks from the Volcanic Caldera, with high Ni, Cr, Co, and V high concentrations. There was a tendency of High Field Strength Elements (HFSE) enrichment and Large Ion Lithophile Elements (LILE) depletion, except for Ba, whose high concentrations may be related to low $\mathrm{K}_{2} \mathrm{O}$ concentrations. The REE present a continuous fractionation pattern characterized by light (LREE) to high rare earth elements (HREE) depletion and lack of Eu anomaly (Eu/Eu* $=0.98 \pm 0.02)$. Compared to REE behavior in the Volcanic Caldera rocks, there is a larger depletion in $\operatorname{HREE}\left(\mathrm{Gd} / \mathrm{Lu}_{\mathrm{cn}}=6.8 \pm 3\right)$, probably related to the weathering of the studied profile. However, the REE fractionation patterns differ from those yielded by saprolites, soils, and bauxites, attesting non-pedogenic characteristics that indicate a preserved geochemical signature of the primordial magma, which corroborates the volcanic caldera evolutionary model in Poços de Caldas.
\end{abstract}

Keywords: Alkaline complex; Pyroclastic deposits; Weathered volcanic tuffs; Evolutionary model. 


\section{INTRODUÇÃO}

A Caldeira Vulcânica de Poços de Caldas é um complexo alcalino com estrutura ligeiramente elíptica com eixo maior de aproximadamente $35 \mathrm{~km}$ na direção NW-SE e eixo menor de aproximadamente $30 \mathrm{~km}$ na direção NE-SW com área aproximada de $800 \mathrm{~km}^{2}$ (Chapman et al., 1991). O modelo sugerido para explicar os processos de intrusão alcalina que resultaram na Caldeira Vulcânica foi proposto por Ellert (1959), sendo ratificado posteriormente por outros pesquisadores (Chapman et al., 1991; Schorscher e Shea, 1992; Holmes et al., 1992). Segundo Ellert (1959), a história evolutiva está relacionada com o domeamento do embasamento, distensões, fraturas e movimentos de massa, seguidos por subsidência, em conjunto com a erosão, resultando no colapso da caldeira e revelando a formação do maciço alcalino interno, junto com o anel circundante ou dique anelar.

Alves (2003) revisou o modelo evolutivo proposto por Ellert (1959), sugerindo uma atividade vulcânica inicial ankaratrítica com formação de tufos, brechas e aglomerados vulcânicos, seguida da construção de um edifício vulcânico de magmatismo nefelínico-sienítico e intercalações de tufos e lapilli tufo. Ainda segundo o autor, há o colapso da caldeira e formação de diques anelares, hiato erosivo, atividades vulcânicas produzindo brechas de conduto e fluxos piroclásticos, finalizando com uma nova atividade magmática de rochas diferenciadas (eudiatila-nefelina sienitos).

Outro modelo sugerido para a evolução da Caldeira Vulcânica de Poços de Caldas foi o de Motoki e Oliveira (1987), Motoki et al. (2008) e Motoki e Sichel (2006), denominado de modelo de corpo intrusivo erodido. Nesse modelo, os autores discutem a exposição dos tipos litológicos, correspondendo estes a um corpo diapírico (corpo intrusivo de material rochoso menos denso que a rocha encaixante) cujo resfriamento provavelmente se iniciou a partir do topo e da borda, gerando fonólitos em posições mais externas e nefelina sienitos em posições mais internas.

Existem poucos estudos sobre rochas piroclásticas na região da Caldeira Vulcânica de Poços de Caldas. Segundo Ulbrich et al. (2002), as rochas vulcanoclásticas se destacam pela dificuldade na sua datação, mas propõem que os eventos vulcanoclásticos ocorreram posteriormente ao assentamento de tinguaítos em idade inferior a 79,1 Ma. Alves (2003), por sua vez, observa que as rochas vulcanoclásticas de fluxo piroclástico estão dispostas sobre camadas de tufos e derrames fonolíticos. Além disso, esse autor subdivide os eventos vulcanoclásticos em pré-colapso e pós-colapso da Caldeira Vulcânica.

As rochas piroclásticas representam uma categoria de rochas vulcânicas formadas pela erupção explosiva do magma, podendo ser encontradas em quase todas as configurações vulcânicas (Jerram e Petford, 2014). São originadas da consolidação de detritos vulcânicos constituídos predominantemente de cinzas, podendo conter também bombas, blocos, lapillis, púmices, escória, além de rochas das paredes e de dutos ejetados com as explosões vulcânicas e suas acumulações na superfície que formam os depósitos piroclásticos (Fisher, 1960; Sommer et al., 2003; Fisher et al., 2006; McClintock e White, 2006; Motoki et al., 2008; Ruggieri et al., 2010).

De forma geral, os depósitos piroclásticos podem ser formados pela suspensão, pela tração ou pelo fluxo de massa dos fragmentos. A suspensão gera os depósitos de queda de piroclastos e o material expelido está subordinado à ação dos gases quentes que promove sua expansão e posterior deposição em áreas restritas (Sommer et al., 2003). A tração gera os depósitos piroclásticos do tipo surge e sua formação ocorre por movimentos laterais arrastados, promovendo uma forma ondular nas camadas (Tucker, 2014). E o fluxo de massa forma os depósitos de fluxo piroclástico com alta concentração de partículas, estando sob o controle da gravidade e podendo atingir condições parcialmente fluidizadas (Tucker, 2014).

Estudos geoquímicos que enfocam elementos traços litófilos, incluindo os elementos terras raras (ETR), são importantes para a identificação dos processos de alteração superficial e diagênese dos depósitos piroclásticos (Zhou et al., 2000; Huber et al., 2003; Muhs e Budahn, 2009). Como existem poucos trabalhos sobre os depósitos piroclásticos de Poços de Caldas, o presente estudo teve como objetivo a caracterização geoquímica de piroclastos intemperizados, visando aprofundar o conhecimento sobre proveniência, padrões de fracionamento e alteração pós-deposição desses materiais.

\section{MATERIAIS E MÉTODOS}

A Caldeira Vulcânica de Poços de Caldas está localizada na borda nordeste da Bacia do Paraná, onde penetrou a denominada Nappe de Socorro-Guaxupé, uma estrutura do embasamento pré-cambriano retrabalhada na Orogenia Brasiliana, e sua cobertura sedimentar pré-neocretácea da Bacia do Paraná (Almeida e Carneiro, 2012; Figura 1).

A idade geocronológica realizada pelo método do K-Ar na Caldeira Vulcânica foi revisada no trabalho de Ulbrich et al. (2002), e os autores concluíram uma idade entre 83 e 64 Ma para a ocorrência do seu magmatismo. De acordo com Ellert (1959), Garda (1990), Chapman et al. (1991), Schorscher e Shea (1992), Holmes et al. (1992), Ulbrich et al. (2002), Alves (2003) e Indústrias Nucleares do Brasil (INB, 2011), o Complexo Alcalino de Poços de Caldas é formado por tinguaítos, nefelina sienitos e foiaitos, fonólitos, lujuaritos e chibinitos, rochas potássicas indiferenciadas, rochas piroclásticas e arenitos (Figura 2).

A escolha do local de estudo teve por base a interpretação das cartas: SP-23-V-C-VI-4 (IBGE, 1972); SF.23-V-D-IV e SF.23-V-C-VI(CODEMIG, 2015); SF.23-V-D (CPRM, 1979); 


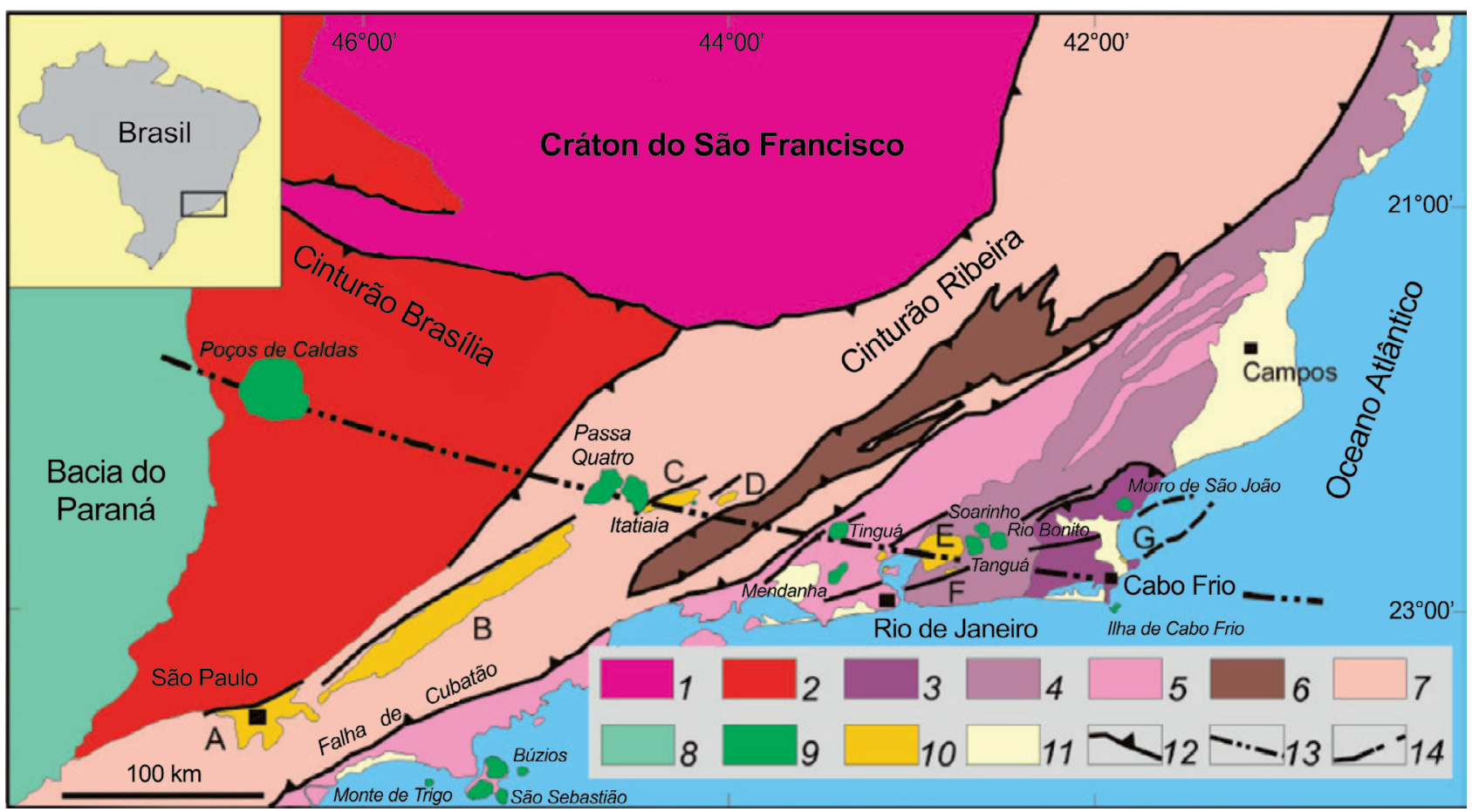

Fonte: Almeida e Carneiro (2012)

Figura 1. Mapa tectônico da região Sudeste do Brasil: (1) Cráton do São Francisco; (2) Cinturão Brasília; (3) Terreno Cabo Frio; (4) Terreno Oriental - Domínio Costeiro; (5) Terreno Oriental - Arco Magmático Rio Negro; (6) Klippe Paraíba do Sul; (7) Terreno Ocidental; (8) Bacia do Paraná; (9) corpos alcalinos do Cretáceo Superior a Eoceno; (10) Bacias do Rift Continental do Sudeste do Brasil (RCSB): A - São Paulo; B - Taubaté; C - Resende; D - Volta Redonda; E - Macacu; F - Itaboraí; G - Barra de São João; (11) sedimentos cenozoicos indiferenciados; (12) falhas reversas, nappes; (13) Alinhamento Magmático de Cabo Frio; (14) limites de grábens do RCSB.

Mapa Geológico do Maciço Alcalino de Poços de Caldas (Ellert, 1959); e Mapa Geológico Regional 2 (INB, 2011). A classificação do tipo de depósito piroclástico teve como base os trabalhos de Sommer et al. (2003), McClintock e White (2006), Motoki et al. (2008), Jerram e Petford (2014) e Tucker (2014). A região onde afloram os depósitos piroclásticos deste estudo apresenta uma encosta convexa à plana de topos aplainados a leste, interflúvio do Córrego das Amoras, acompanhando um alinhamento mais serrano a oeste e um vale aberto amplo do Córrego da Ariranha (Figura 3).

Em cada ponto foi selecionado um nível e coletadas as seguintes amostras:

- P1: amostras P1.1 (inferior) e P1.2 (superior);

- P2: amostras P2.1 (inferior), P2.2 (intermediário) e P2.3 (superior);

- P3: amostras P3.1 (inferior), P3.2 (intermediário) e P3.3 (superior);

- P4: amostras P4.1 (inferior) e P4.2 (superior).

Para coleta de amostras, foram selecionadas amostras totais (matriz + clasto) de cada nível de alteração, separando cerca de 500 g de cada exemplar, acondicionando-os em sacos plásticos devidamente identificados.

O ponto P1 (Figuras 4A e 4B) está localizado nas coordenadas $328.724 \mathrm{~W}$ e $7.587 .171 \mathrm{~S}$ a $1.291 \mathrm{~m}$ de altitude. O afloramento corresponde a um depósito de queda de piroclastos, estando truncado por um depósito de fluxo piroclástico e por um afloramento rochoso saprolitizado. Alves (2003), em trabalho realizado próximo ao perfil, observou a presença de rochas vulcanoclásticas de fluxo piroclástico dispostas sobre camada de tufos e derrames fonolíticos. O afloramento apresenta uma matriz saprolitizada, quebradiça e pouco umedecida com litofácies do tipo lapilli tufo sem estrutura, com clastos de dimensões inferiores a $9 \mathrm{~mm}$, pouco ordenados e envolvidos em uma matriz de cinza grossa de 0,5 a $1 \mathrm{~mm}$ (Figura 4B).

$\mathrm{O}$ ponto $\mathrm{P} 2$ está localizado nas coordenadas $328.444 \mathrm{~W}$ e 7.586.330 S a $1.327 \mathrm{~m}$ de altitude e é formado por um depósito de fluxo piroclástico, tufos e brechas que se encontram ora sotopostos, ora sobrepostos, sugerindo momentos diferentes de deposição. $\mathrm{O}$ afloramento apresenta um depósito de tufo cuja matriz se encontra saprolitizada e ligeiramente 


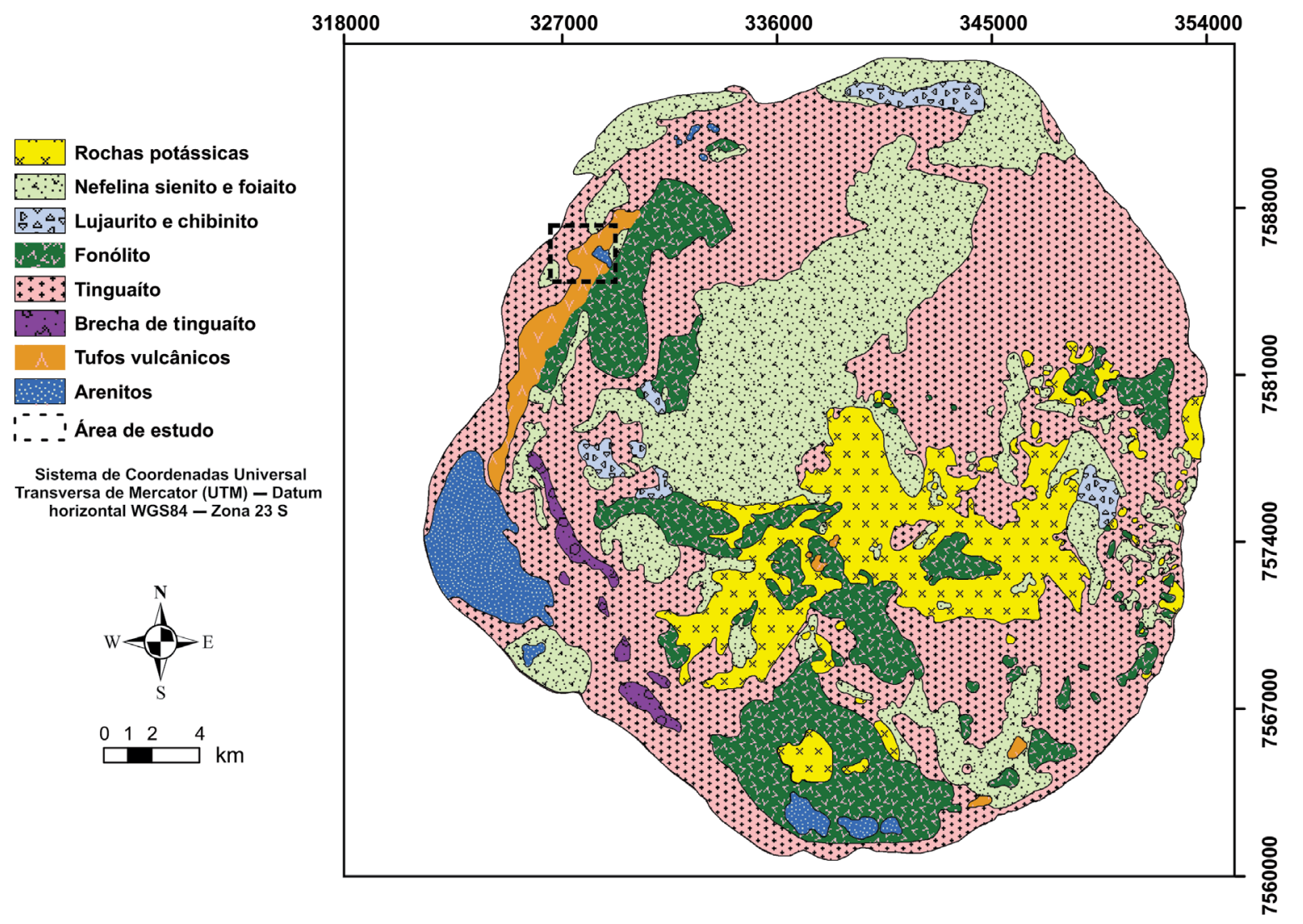

Fonte: modificado de Ellert (1959), Ulbrich et al. (2002) e Indústrias Nucleares do Brasil (INB, 2011).

Figura 2. Mapa geológico do Complexo Alcalino de Poços de Caldas. Destaque para a área de estudo.

umedecida, contendo clastos polimíticos cuja presença pode estar relacionada com a possível formação de fluxos de lahares que se misturaram ou participaram da formação desse depósito. Os tufos apresentam litofácies do tipo lapilli tufo sem estrutura e brechas do tipo tufo brecha indiferenciada sem estrutura e lapilli tufo grosso (Figuras 4C e 4D).

Nas coordenadas $328.066 \mathrm{~W}$ e $7.586 .040 \mathrm{~S}$ a $1.314 \mathrm{~m}$ de altitude, o ponto P3 (Figuras 4E e 4F) corresponde a um depósito de fluxo piroclástico formado por brecha piroclástica saprolitizada com litofácies do tipo tufo brecha indiferenciada sem estrutura e lapilli tufo grosso. Nesse afloramento, também é possível observar blocos sustentados por uma matriz de lapilli tufo saprolitizado e brechas piroclásticas saprolizadas (Figura 4F), semelhantes às encontradas em P2.

$\mathrm{O}$ ponto $\mathrm{P} 4$ apresenta uma litofácies heterogênea, não se observando seleção granulométrica dos clastos, sendo, portanto, classificada como tufo brecha indiferenciada sem estrutura e lapilli tufo grosso, e lapilli tufo com sucessão de cinzas finas (Figuras 4G e 4H). No afloramento, localizado nas coordenadas $328.437 \mathrm{~W}$ e $7.586 .025 \mathrm{~S}$ a $1.323 \mathrm{~m}$ de altitude, existem bombas, nódulos/concreções e lapilli inseridas na matriz saprolitizada. Tal fato sugere que sua formação provavelmente ocorreu por fluxo de piroclastos com bombas arredondadas acrescentadas por rolamento, gerando aglomerados e brechas com clastos de variados tamanhos após a soldagem do depósito.

As amostras coletadas foram encaminhadas à SGS Geosol Laboratórios Ltda na unidade matriz em Vespasiano, Minas Gerais. Para a realização da análise geoquímica, efetuou-se o preparo das amostras (secagem a $105^{\circ} \mathrm{C}$, britagem a $3 \mathrm{~mm}$, homogeneização, quarteamento e pulverização de 250 a $300 \mathrm{~g} \mathrm{em}$ moinho de aço $95 \% 150 \mathrm{mesh}$ ) no laboratório de preparação física de amostras da SGS Geosol Laboratórios Ltda.

No laboratório geoquímico da SGS Geosol Laboratórios Ltda., foram realizadas análises para os principais óxidos $\left(\mathrm{SiO}_{2}, \mathrm{TiO}_{2}, \mathrm{Al}_{2} \mathrm{O}_{3}, \mathrm{Fe}_{2} \mathrm{O}_{3}, \mathrm{MnO}, \mathrm{MgO}, \mathrm{CaO}, \mathrm{Na}_{2} \mathrm{O}, \mathrm{K}_{2} \mathrm{O}\right.$ e $\mathrm{P}_{2} \mathrm{O}_{5}$ ), elementos traços ( $\mathrm{Ba}, \mathrm{Co}, \mathrm{Cs}, \mathrm{Ga}, \mathrm{Hf}, \mathrm{Cr}, \mathrm{Nb}, \mathrm{Rb}$, $\mathrm{Sn}, \mathrm{Sr}, \mathrm{Ta}, \mathrm{Th}, \mathrm{U}, \mathrm{V}, \mathrm{W}, \mathrm{Y}, \mathrm{Zr}, \mathrm{Tl}, \mathrm{Zn}, \mathrm{Cu}, \mathrm{Mo}$ e Ni) e ETR (La, Ce, Pr, Nd, Sm, Eu, Gd, Tb, Dy, Ho, Er, Tm, Yb e Lu). Os principais óxidos, alguns elementos traços $(\mathrm{Ba}, \mathrm{Cr}, \mathrm{Sr}, \mathrm{Zn}$, $\mathrm{Zr} \mathrm{e} \mathrm{V}$ ) e $\mathrm{o}_{2} \mathrm{O}$ foram determinados por fusão com metaborato de lítio por meio de espectrometria de emissão óptica com plasma acoplado indutivamente (Inductively Coupled 

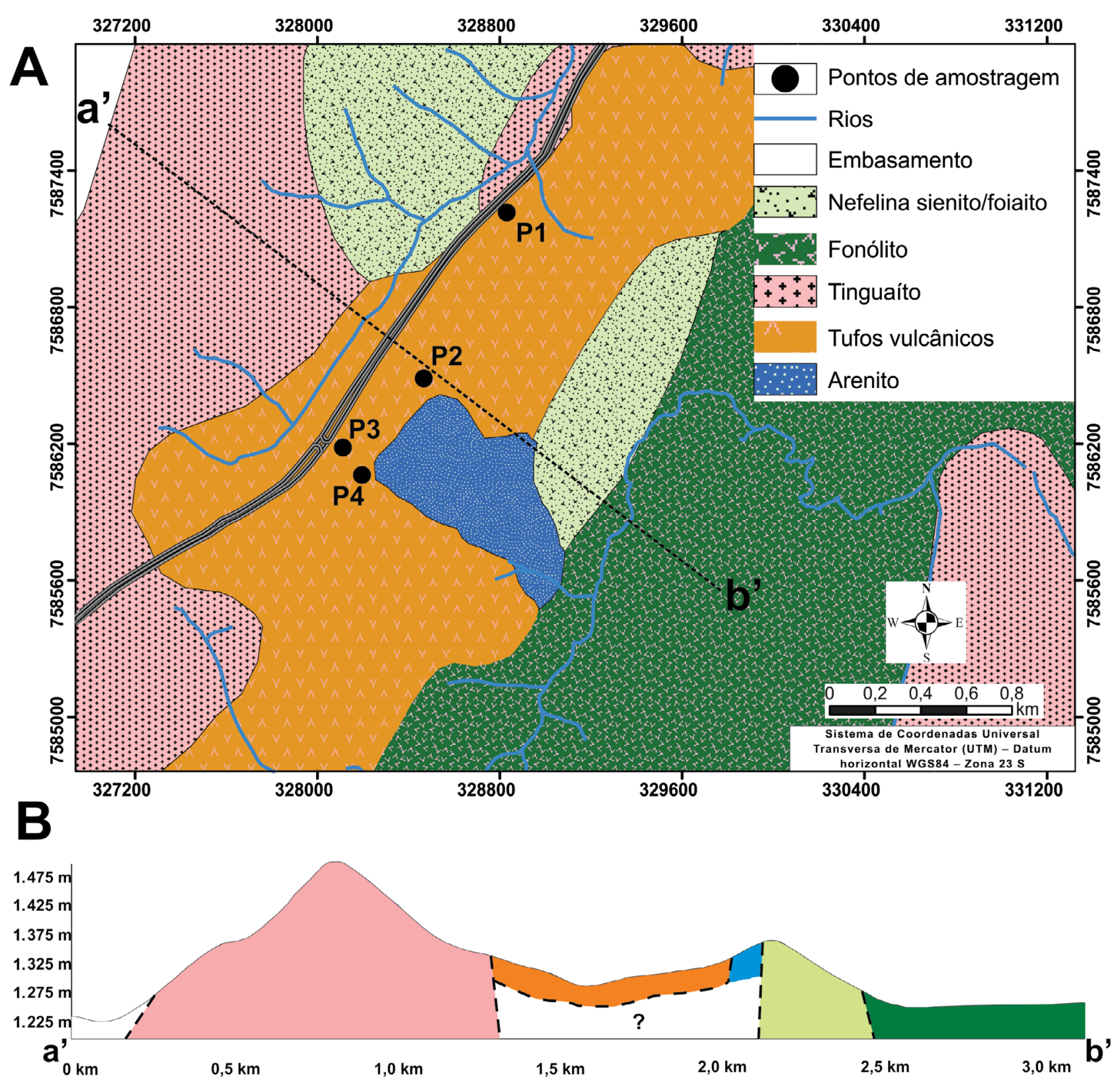

Fonte: modificado de Ellert (1959) e Indústrias Nucleares do Brasil (INB, 2011).

Figura 3. (A) Mapa geológico da área de estudo com localização dos níveis de alteração de piroclastos; (B) perfil de elevação do transecto a'-b'.

Plasma Optical Emission Spectrometry — ICP OES). Já os ETR e outros elementos traços ( $\mathrm{Co}, \mathrm{Cs}, \mathrm{Cu}, \mathrm{Ga}, \mathrm{Hf}, \mathrm{Mo}, \mathrm{Nb}$, $\mathrm{Ni}, \mathrm{Rb}, \mathrm{Sn}, \mathrm{Ta}, \mathrm{Th}, \mathrm{Tl}, \mathrm{U}, \mathrm{W}$ e Y) foram determinados por fusão com metaborato de lítio por meio de espectrometria de massa por plasma acoplado indutivamente (Inductively Coupled Plasma Mass Spectrometry - ICP MS).

Os resultados das análises foram normalizados pela base anidra para os principais óxidos, elementos traços e terras raras pelo Condrito C1 (Sun, 1982; Sun e McDonough, 1989; Evensen et al., 1978). Os dados obtidos foram comparados com os teores contidos nas rochas e materiais alterados de trabalhos de referência realizados anteriormente na Caldeira Vulcânica de Poços de Caldas: nefelina sienitos e fonólitos (Schorscher e Shea, 1992); saprólitos, solos e bauxitas (Valeton et al., 1997); aglomerados diversos (Alves, 2003); nefelina sienitos e tinguaítos (Ulbrich et al., 2005). 

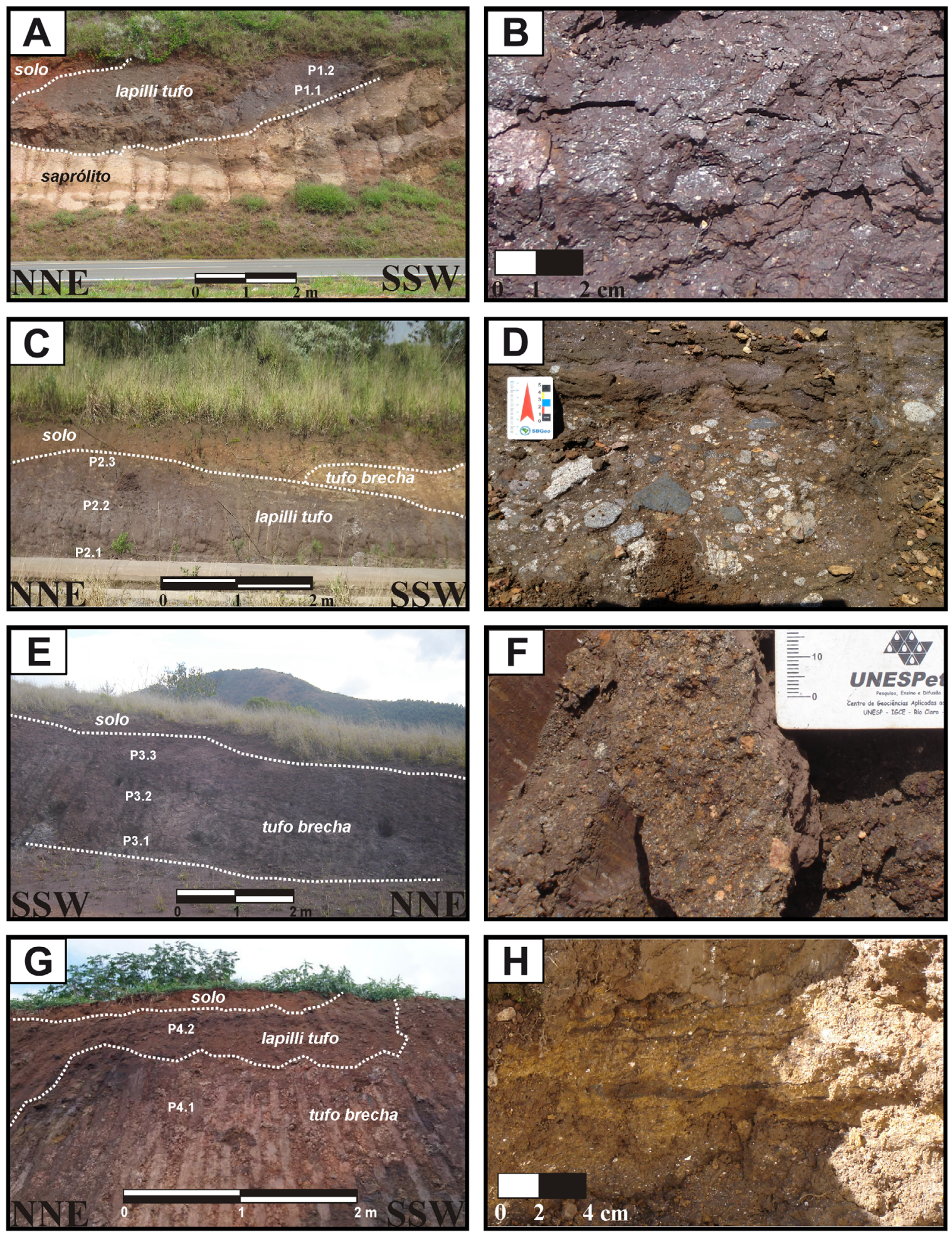

Figura 4. (A) Nível de alteração P1 formado por um depósito de queda e fluxo de piroclastos truncado com material saprolitizado; (B) litofácies do tipo lapilli tufo; (C) depósito de tufo brecha piroclástica truncado com litofácies do tipo lapilli tufo do nível de alteração P2; (D) clastos polimíticos na matriz de tufo com fraturas paralelas; (E) feições de depósito de fluxo piroclástico e litofácies do tipo tufo brecha indiferenciada sem estrutura no nível de alteração P3; (F) bloco sustentado por uma matriz de lapilli tufo saprolitizado; $(G)$ nível de alteração P4 lapilli tufo e tufo brecha; $(H)$ lapilli tufo com sucessão de cinzas finas. 


\section{RESULTADOS E DISCUSSÃO}

\section{Elementos maiores}

Os resultados das análises químicas (Tabela 1) e os diagramas de Harker (Figura 5) indicam que P4.2 se destaca dos demais pontos deste estudo pela dispersão acentuada, causada pelas relativamente baixas concentrações de $\mathrm{SiO}_{2}$ e $\mathrm{Al}_{2} \mathrm{O}_{3}$. No entanto, as concentrações de $\mathrm{Al}_{2} \mathrm{O}_{3}$ em P4.2 são próximas às amostras de fonólito e nefelina sienito de Schorscher e Shea (1992) e Ulbrich et al. (2005).

A amostra P3.3 também apresenta dispersão causada pela menor concentração de $\mathrm{SiO}_{2}$, no entanto com maior concentração de $\mathrm{Al}_{2} \mathrm{O}_{3}$. As amostras dos pontos analisados neste

Tabela 1. Elementos maiores em \% de óxidos, traços e terras raras em ppm.

\begin{tabular}{|c|c|c|c|c|c|c|c|c|c|c|c|c|}
\hline & LD & P1.1 & $\mathrm{P} 1.2$ & P2.1 & P2.2 & P2.3 & P3.1 & P3.2 & P3.3 & P4.1 & P4.2 & CC1 \\
\hline $\mathrm{SiO}_{2}$ & 0,01 & 27,28 & 26,32 & 29,75 & 34,47 & 26,45 & 28,98 & 28,26 & 15,97 & 22,43 & 4,94 & - \\
\hline $\mathrm{TiO}_{2}$ & 0,01 & 7,74 & 7,58 & 7,20 & 5,44 & 8,12 & 5,61 & 9,60 & 6,67 & 8,59 & 11,38 & - \\
\hline $\mathrm{Al}_{2} \mathrm{O}_{3}$ & 0,01 & 24,57 & 24,32 & 28,72 & 30,57 & 26,15 & 28,39 & 26,29 & 34,29 & 22,21 & 11,85 & - \\
\hline $\mathrm{Fe}_{2} \mathrm{O}_{3}$ & 0,01 & 31,35 & 32,91 & 24,58 & 21,32 & 28,78 & 26,87 & 25,95 & 28,01 & 33,84 & 52,51 & - \\
\hline $\mathrm{MnO}$ & 0,01 & 0,18 & 0,14 & 0,26 & 0,14 & 0,26 & 0,17 & 0,07 & 0,18 & 0,41 & 1,23 & - \\
\hline $\mathrm{MgO}$ & 0,01 & 0,03 & 0,04 & 0,04 & 0,06 & 0,08 & 0,04 & 0,02 & 0,04 & 0,03 & 0,03 & - \\
\hline $\mathrm{CaO}$ & 0,01 & 0,10 & 0,10 & 0,08 & 0,06 & 0,13 & 0,10 & 0,09 & 0,13 & 0,31 & 0,70 & - \\
\hline $\mathrm{Na}_{2} \mathrm{O}$ & 0,01 & 0,02 & 0,01 & 0,02 & 0,02 & 0,02 & 0,01 & 0,01 & 0,02 & 0,03 & 0,06 & - \\
\hline $\mathrm{K}_{2} \mathrm{O}$ & 0,01 & 0,05 & 0,03 & 0,07 & 0,12 & 0,09 & 0,03 & 0,05 & 0,08 & 0,11 & 0,14 & - \\
\hline $\mathrm{P}_{2} \mathrm{O}_{5}$ & 0,01 & 0,39 & 0,31 & 0,40 & 0,20 & 0,37 & 0,59 & 0,53 & 0,69 & 1,49 & 3,99 & - \\
\hline $\mathrm{H}_{2} \mathrm{O}$ & 0,01 & 8,67 & 9,03 & 10,79 & 11,15 & 10,64 & 11,14 & 10,45 & 15,27 & 9,99 & 8,18 & - \\
\hline Soma & 0,01 & 100,38 & 100,79 & 101,91 & 103,55 & 101,09 & 101,93 & 101,32 & 101,35 & 99,44 & 95,01 & - \\
\hline $\mathrm{Ni}$ & 5,00 & 95,00 & 74,00 & 91,00 & 98,00 & 95,00 & 28,00 & 47,00 & 35,00 & 78,00 & 133,00 & $9.900^{*}$ \\
\hline $\mathrm{Cr}$ & 0,01 & 821,05 & 821,05 & 205,26 & 205,26 & 342,11 & 68,42 & 547,37 & 205,26 & 136,84 & 273,68 & $2.430^{*}$ \\
\hline Co & 0,50 & 6,70 & 6,30 & 18,30 & 16,60 & 29,00 & 17,70 & 13,50 & 19,40 & 57,80 & 102,80 & $480^{*}$ \\
\hline V & 5,00 & 665,00 & 595,00 & 860,00 & 794,00 & 891,00 & $1.460,00$ & 912,00 & $1.108,00$ & 626,00 & $1.463,00$ & $42^{*}$ \\
\hline $\mathrm{Hf}$ & 0,05 & 21,70 & 21,74 & 19,97 & 15,08 & 24,73 & 29,28 & 17,95 & 27,23 & 39,24 & 48,27 & - \\
\hline Cs & 0,05 & 0,74 & 0,73 & 0,40 & 0,32 & 0,39 & 0,11 & 0,10 & 0,58 & 0,18 & 0,19 & $0,188^{\star \star}$ \\
\hline $\mathrm{Rb}$ & 0,20 & 2,00 & 1,70 & 3,10 & 4,80 & 3,50 & 1,20 & 1,30 & 2,00 & 3,80 & 4,10 & $2,320^{\star \star}$ \\
\hline $\mathrm{Ba}$ & 10,00 & $1.262,00$ & $1.149,00$ & $1.948,00$ & 954,00 & $1.833,00$ & $2.497,00$ & $2.661,00$ & $2.815,00$ & $3.293,00$ & $7.117,00$ & $2,410^{* *}$ \\
\hline Th & 0,10 & 28,5 & 27,20 & 31,90 & 22,20 & 40,80 & 16,50 & 10,40 & 46,80 & 42,80 & 88,50 & $0,029^{\star *}$ \\
\hline$U$ & 0,05 & 11,41 & 9,94 & 8,57 & 8,28 & 10,26 & 7,42 & 8,86 & 10,97 & 12,58 & 20,36 & $0,008^{\star *}$ \\
\hline $\mathrm{Ta}$ & 0,05 & 15,47 & 15,00 & 15,23 & 10,03 & 18,39 & 11,34 & 12,62 & 19,51 & 21,04 & 31,85 & $0,014^{\star *}$ \\
\hline $\mathrm{Nb}$ & 0,05 & 306,43 & 290,89 & 332,36 & 251,98 & 436,74 & 431,31 & 229,75 & 842,57 & 596,37 & $1.000,00$ & $0,246^{\star *}$ \\
\hline La & 0,10 & 356,00 & 232,20 & 313,80 & 210,00 & 414,40 & 382,40 & 287,60 & 453,40 & 547,80 & $1.484,00$ & $0,237^{\star *}$ \\
\hline $\mathrm{Ce}$ & 0,10 & 557,00 & 392,00 & 486,50 & 317,30 & 670,60 & 525,80 & 446,50 & 792,90 & 800,90 & $2.122,00$ & $0,612^{\star \star}$ \\
\hline $\mathrm{Sr}$ & 10,00 & 857,00 & 873,00 & 656,00 & 397,00 & 536,00 & $1.125,00$ & 545,00 & $1.416,00$ & $1.763,00$ & $6.210,00$ & $7,260^{\star \star}$ \\
\hline $\mathrm{Nd}$ & 0,10 & 220,70 & 182,00 & 201,60 & 131,90 & 244,40 & 198,00 & 202,70 & 245,20 & 449,80 & $1.018,00$ & $0,467^{\star *}$ \\
\hline $\mathrm{Sm}$ & 0,10 & 34,10 & 31,00 & 32,20 & 21,50 & 36,70 & 30,90 & 35,30 & 37,10 & 66,00 & 148,80 & $0,153^{\star \star}$ \\
\hline $\mathrm{Zr}$ & 10,0 & $1.103,00$ & $1.058,00$ & 984,00 & 782,00 & $1.220,00$ & $1.758,00$ & 734,00 & $1.558,00$ & $1.884,00$ & $2.847,00$ & $3,870^{\star \star}$ \\
\hline Y & 0,05 & 47,97 & 46,21 & 51,81 & 36,02 & 59,89 & 63,59 & 38,45 & 76,68 & 89,86 & 230,62 & $1,570^{\star \star}$ \\
\hline $\mathrm{La}$ & 0,10 & 356,00 & 232,20 & 313,80 & 210,00 & 414,40 & 382,40 & 287,60 & 453,40 & 547,80 & $1.484,00$ & $0,24460^{\star \star \star}$ \\
\hline $\mathrm{Ce}$ & 0,10 & 557,00 & 392,00 & 486,50 & 317,30 & 670,60 & 525,80 & 446,50 & 792,90 & 800,90 & $2.122,00$ & $0,63790^{\star \star \star}$ \\
\hline $\operatorname{Pr}$ & 0,05 & 63,56 & 47,92 & 57,39 & 37,98 & 72,51 & 59,96 & 53,08 & 74,59 & 122,38 & 294,65 & $0,09637^{\star \star \star \star}$ \\
\hline $\mathrm{Nd}$ & 0,10 & 220,70 & 182,00 & 201,60 & 131,90 & 244,40 & 198,00 & 202,70 & 245,20 & 449,80 & $1.018,00$ & $0,47380^{\star \star \star}$ \\
\hline $\mathrm{Sm}$ & 0,10 & 34,10 & 31,00 & 32,20 & 21,50 & 36,70 & 30,90 & 35,30 & 37,10 & 66,00 & 148,80 & $0,15400^{\text {*** }}$ \\
\hline Eu & 0,05 & 9,13 & 8,72 & 8,76 & 5,74 & 9,72 & 8,48 & 10,15 & 10,44 & 16,89 & 38,86 & $0,05802^{\star \star \star}$ \\
\hline $\mathrm{Gd}$ & 0,05 & 22,67 & 22,95 & 22,33 & 14,84 & 25,54 & 22,73 & 26,12 & 28,10 & 42,65 & 101,06 & $0,20430^{\text {*** }}$ \\
\hline $\mathrm{Tb}$ & 0,05 & 2,71 & 2,58 & 2,66 & 1,83 & 3,02 & 2,84 & 3,00 & 3,58 & 4,87 & 11,81 & 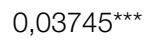 \\
\hline Dy & 0,05 & 12,35 & 12,38 & 12,83 & 9,26 & 14,87 & 13,89 & 13,09 & 18,01 & 22,60 & 55,97 & $0,25410^{\star \star \star \star}$ \\
\hline $\mathrm{Ho}$ & 0,05 & 1,90 & 1,97 & 2,10 & 1,48 & 2,42 & 2,34 & 1,83 & 2,97 & 3,66 & 9,29 & $0,05670^{\star \star \star \star}$ \\
\hline Er & 0,05 & 4,44 & 4,76 & 5,03 & 3,71 & 5,84 & 5,75 & 3,84 & 7,54 & 8,76 & 21,65 & $0,16600^{\star \star \star}$ \\
\hline
\end{tabular}


Tabela 1. Continuação.

\begin{tabular}{|c|c|c|c|c|c|c|c|c|c|c|c|c|}
\hline & LD & P1.1 & P1.2 & P2.1 & P2.2 & P2.3 & P3.1 & P3.2 & P3.3 & P4.1 & P4.2 & CC1 \\
\hline Tm & 0,05 & 0,53 & 0,57 & 0,61 & 0,46 & 0,70 & 0,75 & 0,40 & 0,93 & 1,03 & 2,50 & $0,02561^{\star \star \star}$ \\
\hline $\mathrm{Yb}$ & 0,10 & 2,90 & 3,10 & 3,40 & 2,80 & 4,00 & 4,50 & 2,00 & 5,70 & 5,60 & 14,10 & $0,16510^{\star \star \star}$ \\
\hline$\underline{\mathrm{Lu}}$ & 0,05 & 0,38 & 0,40 & 0,43 & 0,37 & 0,53 & 0,64 & 0,23 & 0,74 & 0,71 & 1,87 & $0,02539^{\star \star \star}$ \\
\hline$\overline{(\Sigma \mathrm{ETR})_{\mathrm{nc}}}$ & - & $4.178,00$ & $3.147,00$ & $3.786,00$ & $2.523,00$ & $4.834,00$ & $4.174,00$ & $3.610,00$ & $5.311,00$ & $7.081,00$ & $17.817,00$ & - \\
\hline$(\Sigma E T R L)_{n c}$ & - & $3.833,00$ & $2.797,00$ & $3.427,00$ & $2.267,00$ & $4.420,00$ & $3.774,00$ & $3.258,00$ & $4.809,00$ & $6.434,00$ & $16.236,00$ & - \\
\hline$(\Sigma \mathrm{ETRP})_{\mathrm{nc}}$ & - & 345,00 & 350,00 & 359,00 & 256,00 & 414,00 & 400,00 & 352,00 & 502,00 & 647,00 & $1.581,00$ & - \\
\hline$(\mathrm{La} / \mathrm{Eu})_{\mathrm{nc}}$ & - & 9,00 & 6,00 & 8,00 & 9,00 & 10,00 & 11,00 & 7,00 & 10,00 & 8,00 & 9,00 & - \\
\hline$(\mathrm{Gd} / \mathrm{Lu})_{\mathrm{nc}}$ & - & 7,00 & 7,00 & 6,00 & 5,00 & 6,00 & 4,00 & 14,00 & 5,00 & 7,00 & 7,00 & - \\
\hline$(\mathrm{La} / \mathrm{Lu})_{\mathrm{nc}}$ & - & 97,00 & 60,00 & 76,00 & 59,00 & 81,00 & 62,00 & 130,00 & 64,00 & 80,00 & 82,00 & - \\
\hline $\mathrm{Eu} / \mathrm{Eu}^{*}$ & - & 1,00 & 0,99 & 0,99 & 0,98 & 0,97 & 0,97 & 1,02 & 0,98 & 0,97 & 0,96 & - \\
\hline $\mathrm{Ce} / \mathrm{Ce}^{*}$ & - & 0,89 & 0,89 & 0,87 & 0,85 & 0,93 & 0,83 & 0,87 & 1,03 & 0,75 & 0,77 & - \\
\hline
\end{tabular}

LD: limite de detecção; CC1: condritos C1; $\Sigma$ ETR: soma das concentrações dos elementos terras raras; nc: normalizado pelo condrito; $\Sigma E T R L:$ soma das concentrações dos elementos terras raras leves; $\Sigma$ ETRP: soma das concentrações dos elementos terras raras pesados; $\mathrm{Eu} / \mathrm{Eu}^{*}: \mathrm{Eu}_{\mathrm{n}} /\left(\mathrm{Sm}_{\mathrm{n}} \times \mathrm{Gd}_{\mathrm{n}}\right)^{0.5} ; \mathrm{Ce} / \mathrm{Ce}^{*}: \mathrm{Ce}_{\mathrm{n}}{ }^{\prime}$

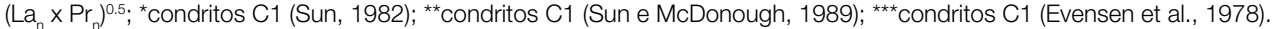

estudo apresentam concentrações de $\mathrm{TiO}_{2}$ similares entre si e superiores às amostras de Schorscher e Shea (1992), Alves (2003) e Ulbrich et al. (2005), ocorrendo o mesmo com o $\mathrm{Fe}_{2} \mathrm{O}_{3}$ que se acumula nos níveis superiores de cada ponto amostrado (P1.2, P2.3, P3.3 e P4.2).

A maior concentração de $\mathrm{MnO}$ foi observada no ponto P4.2 e a menor no ponto P3.2, próximo a um fragmento de rocha ultramáfica (PDC-11-4) do estudo de Alves (2003). Já as concentrações de $\mathrm{H}_{2} \mathrm{O}$ e $\mathrm{P}_{2} \mathrm{O}_{5}$ nos pontos estudados são superiores às de nefelina sienitos, fonólitos e tinguaítos de Schorscher e Shea (1992) e Ulbrich et al. (2005), porém possuem concentração inferior a um fragmento de rocha ultramáfica PDC-11-4 e superior a carbonatitos (PDC-11CA, PDC-11CB e PDC-11C) de Alves (2003).

As concentrações de $\mathrm{K}_{2} \mathrm{O}, \mathrm{Na}_{2} \mathrm{O}, \mathrm{CaO}$ e $\mathrm{MgO}$ são inferiores àquelas de Schorscher e Shea (1992), Alves (2003) e Ulbrich et al. (2005), e o ponto P4.2 apresenta as mais altas concentrações desses óxidos entre as amostras deste estudo. Os pontos P4.1 e P4.2 também apresentam as mais altas concentrações de $\mathrm{CaO}$ quando comparados às demais amostras analisadas neste estudo.

O intemperismo pode causar a mobilização de certos elementos nos minerais da rocha sã, especialmente aqueles suscetíveis à lixiviação, como o $\mathrm{Mg}$, o Ca, o K e o Na. Por meio do diagrama Nesbitt e Young $(1984,1989)$ na Figura 6A, é possível identificar o estágio do intemperismo das amostras estudadas. Os piroclastos ficam agrupados em um campo distante do eixo $\left(\mathrm{CaO}+\mathrm{Na}_{2} \mathrm{O}\right)$, portanto na região de menor concentração desses óxidos, provavelmente em razão da retirada dos cátions durante o intemperismo.

Considerando o estágio de intemperismo nas amostras dos piroclastos, verificou-se também o seu processo de laterização por meio do diagrama ternário $\mathrm{SiO}_{2} / \mathrm{Fe}_{2} \mathrm{O}_{3} /$ $\mathrm{Al}_{2} \mathrm{O}_{3}$ de Schellmann $(1994,2003)$ (Figura 6B). No diagrama é possível verificar laterização intensa no ponto $\mathrm{P} 4.2$ com forte concentração de $\mathrm{Fe}_{2} \mathrm{O}_{3}$ e laterização moderada no ponto P3.3.

O intemperismo (Figura 6), segundo Augustin et al. (2013), pode ter causado a acumulação relativa de $\mathrm{Fe}, \mathrm{Al}$ e Mn ao mesmo tempo em que os cátions metálicos $\mathrm{Ca}^{2+}$, $\mathrm{Mg}^{2+}, \mathrm{K}^{+}, \mathrm{Na}^{+}$e sílica são lixiviados pela precipitação e/ou oscilação de nível freático. A acumulação absoluta pode ter ocorrido pelo aporte externo ao perfil de $\mathrm{Fe}, \mathrm{Al}$ e $\mathrm{Mn}$ pela ação da gravidade, tanto por enxurradas que remobilizam os materiais na superfície quanto pelos corpos d'água que podem conter precipitados de óxidos e hidróxidos de $\mathrm{Fe}$ e Mn (Augustin et al., 2013).

As ações climáticas também podem ter influenciado na configuração geoquímica dos piroclastos estudados. Segundo Holmes et al. (1992), a presença de jazidas de bauxita evidencia o domínio pretérito de um clima semiárido dominante na América do Sul durante o Paleoceno (65-55 Ma), um clima úmido com intemperismo químico associado de forma prolongada no Eoceno (55-36 Ma), retornando para condições mais secas durante o Neogeno (23-2 Ma). Essas condições, provavelmente, afetaram os processos geoquímicos, condicionando padrões de enriquecimento e/ou perda de determinados elementos maiores.

\section{Elementos traços}

As concentrações dos elementos traços variam pouco entre as amostras de piroclastos (Figura 7), havendo maior enriquecimento no ponto P4.2. Tal enriquecimento pode estar relacionado ao processo de intemperismo, com lixiviação de elementos maiores, resultando no enriquecimento relativo dos seus elementos menos móveis. Em todas as amostras, observa-se tendência de enriquecimento na maioria dos elementos de alto potencial iônico (High Field Strength Elements - HFSE) e empobrecimento em 

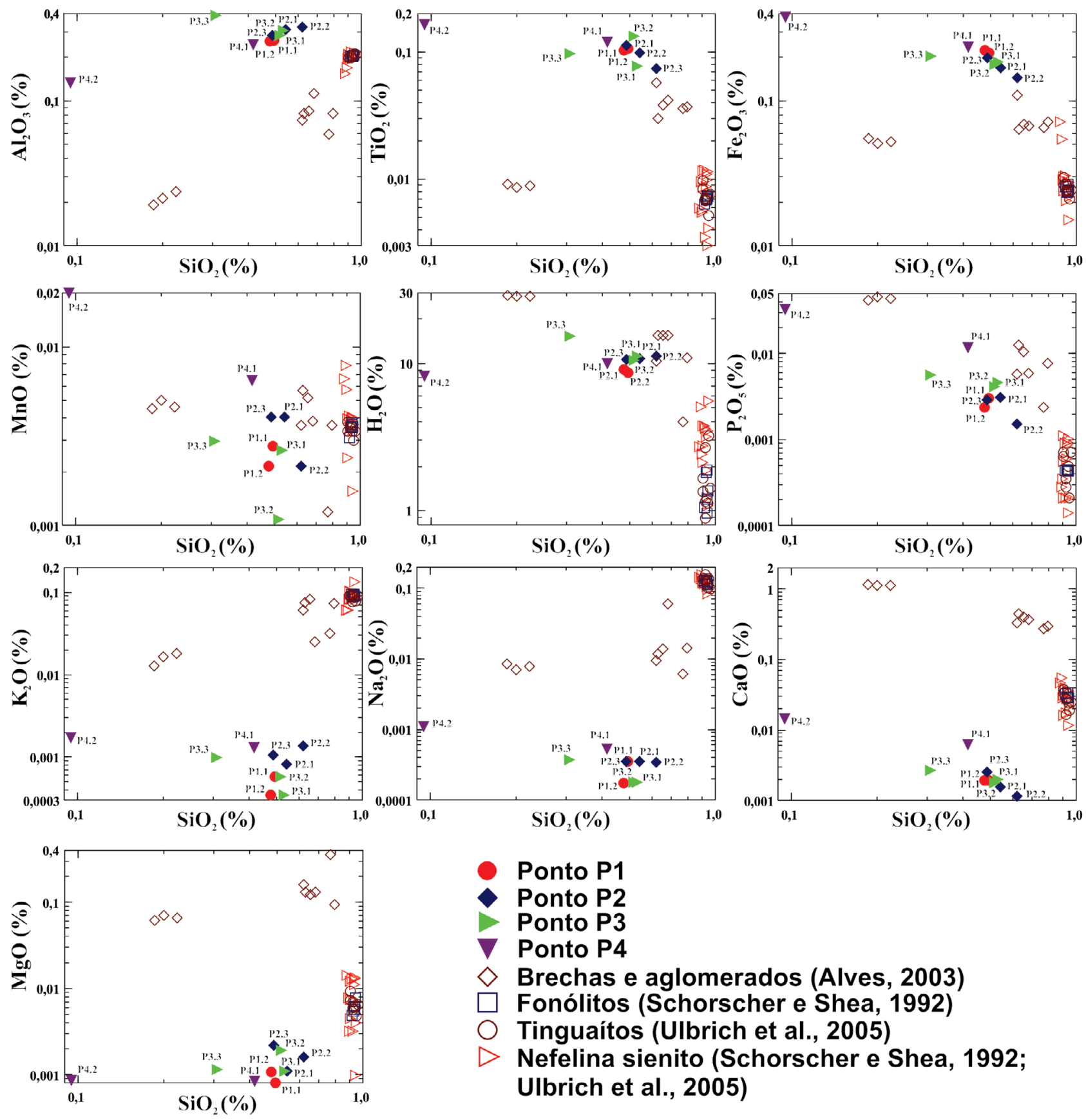

Ponto P1

Ponto P2

$\checkmark$ Ponto P4

$\diamond$ Brechas e aglomerados (Alves, 2003)

$\square$ Fonólitos (Schorscher e Shea, 1992)

Tinguaítos (Ulbrich et al., 2005)

$\triangle$ Nefelina sienito (Schorscher e Shea, 1992;

Ulbrich et al., 2005)

Figura 5. Diagramas de Harker: $\mathrm{SiO}_{2}$ versus $\mathrm{Al}_{2} \mathrm{O}_{3}, \mathrm{TiO}_{2}, \mathrm{Fe}_{2} \mathrm{O}_{3}, \mathrm{MnO}, \mathrm{H}_{2} \mathrm{O}, \mathrm{P}_{2} \mathrm{O}_{5}, \mathrm{~K}_{2} \mathrm{O}, \mathrm{Na} \mathrm{O}_{2} \mathrm{CaO}$ e MgO.

elementos litófilos de grande raio iônico (Large Ion Lithophile Elements - LILE) - exceto o Ba.

As concentrações de elementos HFSE nos piroclastos são similares às das amostras de nefelina sienitos e tinguaítos de Ulbrich et al. (2005) - conforme Figuras 7A e $7 \mathrm{C}$ - e com padrão diferente das amostras de fonólitos de Schorscher e Shea (1992) (Figura 7B). Apesar de as amostras referentes à matriz de brecha de fluxo piroclástico de Alves (2003) apresentarem anomalias negativas e positivas para o U e o Ta, respectivamente, também é observado padrão de fracionamento similar aos piroclastos (Figura 7D). As baixas concentrações de $\mathrm{Cs}$ e $\mathrm{Rb}$ podem estar relacionadas ao baixo potencial iônico desses elementos (LILE), o que os torna suscetíveis à lixiviação (Rollinson, 1993). 


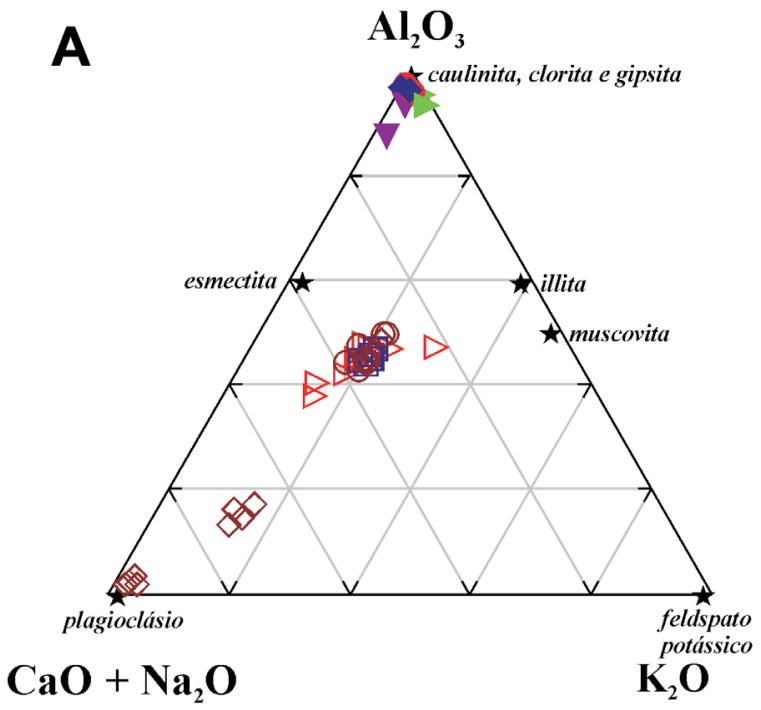

$\mathrm{CaO}+\mathrm{Na}_{2} \mathrm{O}$

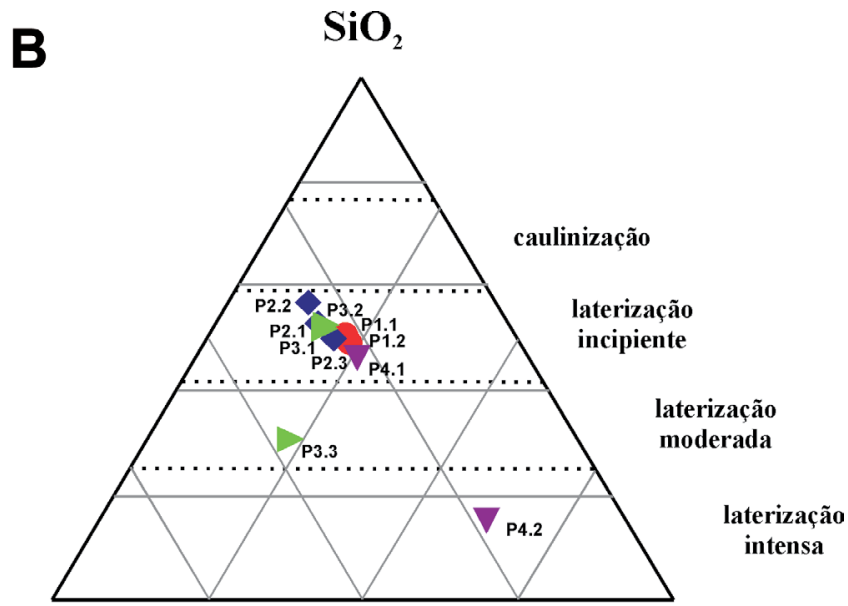

$\mathrm{Al}_{2} \mathrm{O}_{3}$

$\mathrm{Fe}_{2} \mathrm{O}_{3}$

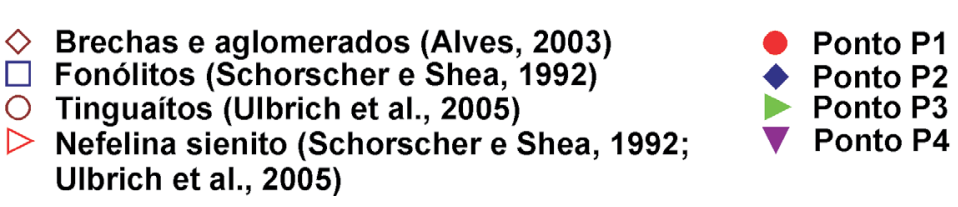

Figura 6. (A) Diagrama ternário de Nesbitt e Young $\left(1984\right.$, 1989) com os principais óxidos $\left(\mathrm{Na}_{2} \mathrm{O}+\mathrm{CaO}\right)-\mathrm{Al}_{2} \mathrm{O}_{3}-\mathrm{K}_{2} \mathrm{O}$ em proporções moleculares mostrando o comportamento das amostras de piroclastos; (B) diagrama ternário de Schellmann $(1994,2003)\left(\mathrm{SiO}_{2}, \mathrm{Fe}_{2} \mathrm{O}_{3}, \mathrm{Al}_{2} \mathrm{O}_{3}\right)$ mostrando o comportamento das amostras de piroclastos frente ao intemperismo.

As altas concentrações de Ba nos piroclastos, associadas às baixas concentrações de $\mathrm{K}_{2} \mathrm{O}$, podem indicar, segundo Mason (1971) e Green (1980), um processo de substituição, ao contrário das amostras de fonólitos, nefelina sienitos e tinguaítos de Schorscher e Shea (1992) e Ulbrich et al. (2005), que apresentam anomalias negativas de Ba e maior $\%$ de $\mathrm{K}_{2} \mathrm{O}$. Além disso, também se deve considerar os processos geoquímicos de intemperismo, que condicionam enriquecimento e/ou perda de elementos (Figura 7).

$\mathrm{Na}$ Figura 8A, as concentrações de $\mathrm{Ni}$ e $\mathrm{Cr}$ são mais elevadas nos piroclastos quando comparadas às de fonólito de Schorscher e Shea (1992). As concentrações de Co são relativamente parecidas com as amostras de fonólitos e nefelina sienitos de Schorscher e Shea (1992) e Ulbrich et al. (2005). Já as concentrações de V são mais acentuadas nos piroclastos, superiores às das amostras de fonólitos, nefelina sienitos e tinguaítos de Schorscher e Shea (1992) e Ulbrich et al. (2005).

Os piroclastos foram comparados com as brechas e os aglomerados de Alves (2003) (Figura 8B). Com relação às amostras de Alves (2003), amostras das mais variadas origens - coletadas por esse autor na Caldeira Vulcânica - foram utilizadas nos diagramas, como granitoides encontrados em brechas, diabásios encontrados em brechas, blocos e fragmentos de ankaratrito encontrados em aglomerados.
Essas amostras estão relacionadas às atividades vulcânicas iniciais e à construção do edifício vulcânico (magmatismo pré-colapso), segundo estudos de Alves (2003). Com isso, verifica-se um padrão mais equivalente com as amostras de ankaratrito, fragmento de rocha ultramáfica e matriz de brecha piroclástica. Além disso, a alta concentração dos elementos $\mathrm{Ni}, \mathrm{Cr}$, Co e $\mathrm{V}$ nos piroclastos deste estudo (Figura $8 \mathrm{~B}$ ) pode estar relacionada com prováveis eventos de ejeção, ou fluxo de lahares, para então serem agregados junto à matriz do depósito após seu resfriamento e sua consolidação.

\section{Elementos terras raras}

A Tabela 1 contém as somas das concentrações dos elementos terras raras leves - ETRL ( $\sum$ ETRL) e dos elementos terras raras pesados - ETRP ( $\sum$ ETRP), as razões normalizadas $\mathrm{La} / \mathrm{Eu}, \mathrm{Gd} / \mathrm{Lu}$ e La/Lu, os cálculos das anomalias de európio e cério. Na Tabela 2 são mostrados os cálculos da média da razão e do desvio padrão das amostras dos perfis e das amostras de fonólitos, nefelina sienitos e tinguaítos de Schorscher e Shea (1992) e Ulbrich et al. (2005), estando todos normalizados com os dados do condrito carbonáceo C1 de Evensen et al. (1978). Com base nos valores da Tabela 2, observa-se maior fracionamento das amostras 


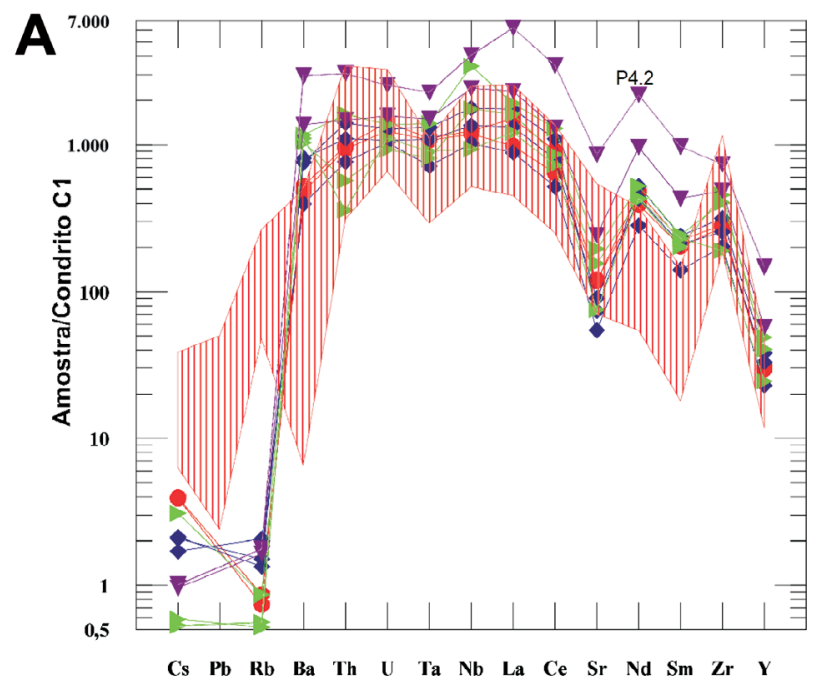

B
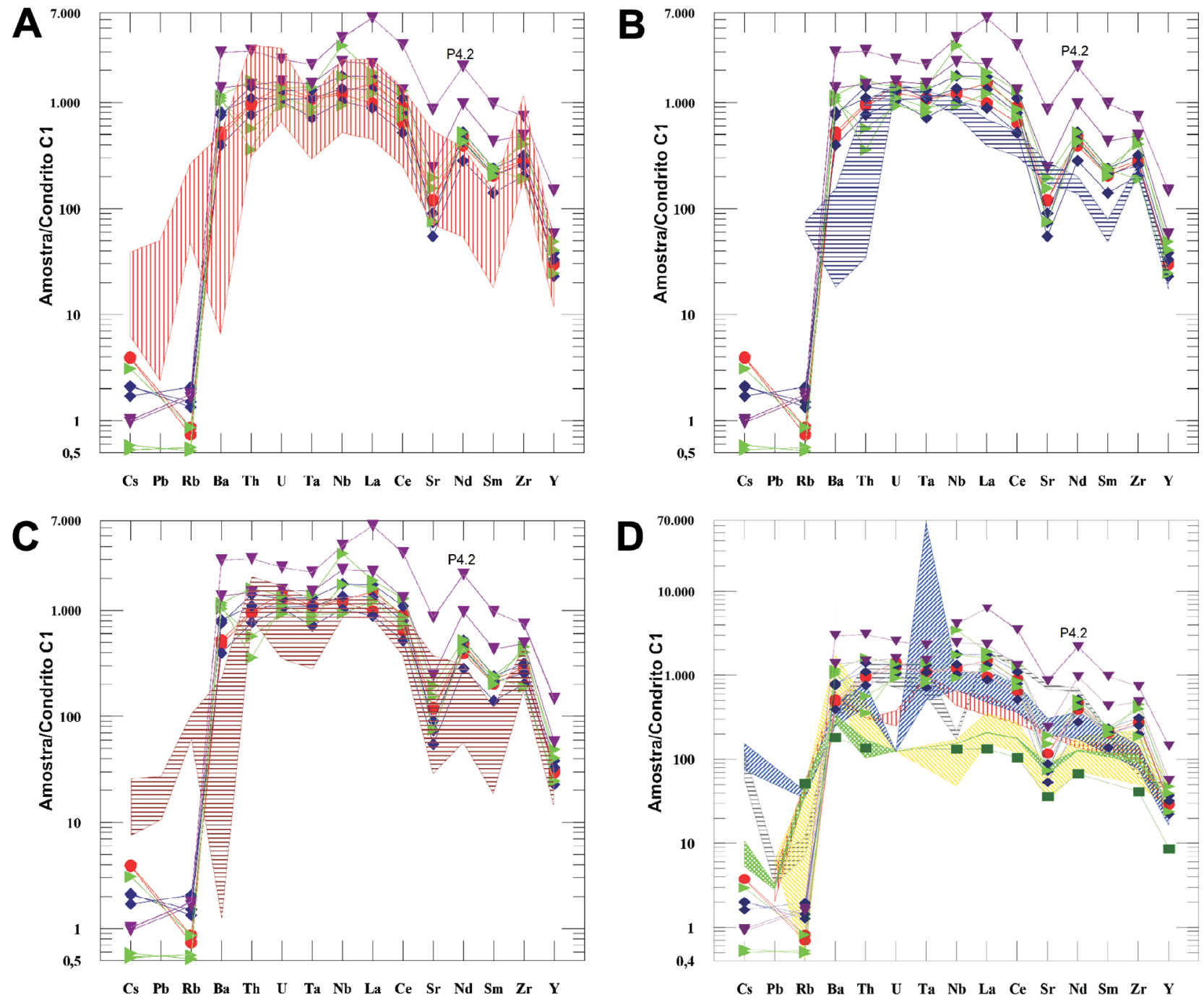

D

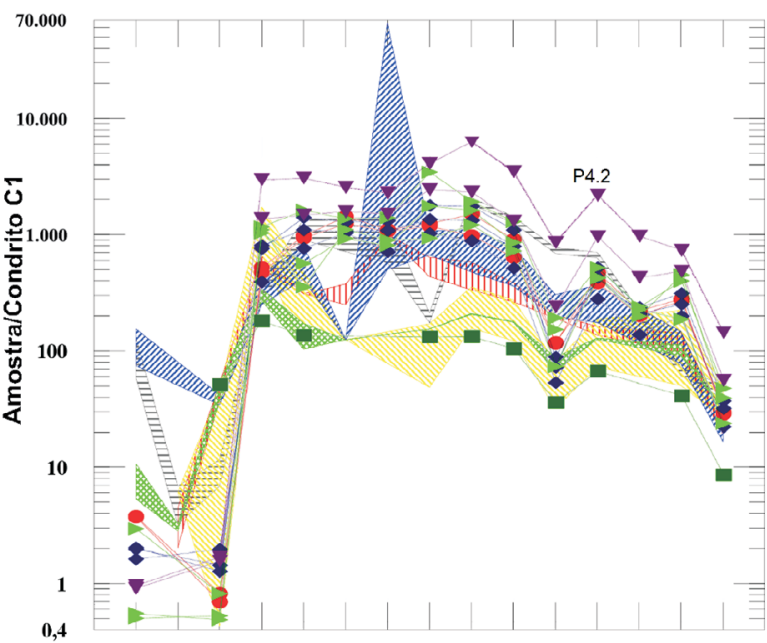

$\begin{array}{lllllllllllllll}\text { Cs } & \mathrm{Pb} & \mathrm{Rb} & \mathrm{Ba} & \mathrm{Th} & \mathrm{U} & \mathrm{Ta} & \mathrm{Nb} & \mathrm{La} & \mathrm{Ce} & \mathrm{Sr} & \mathrm{Nd} & \mathrm{Sm} & \mathrm{Zr} & \mathrm{Y}\end{array}$

$$
\begin{aligned}
& \text { P1 } P \text { P2 } P \text { P3 } \nabla \text { P4 } \\
& \text { B - Nefelina sienito (Schorscher e Shea, 1992; Ulbrich et al., 2005) } \\
& \text { C - Tinguaito (Ulbrich et al., 2005) }
\end{aligned}
$$

\begin{tabular}{|c|c|}
\hline \multicolumn{2}{|c|}{ D - Brechas e aglomerados (Alves, 2003) } \\
\hline $\begin{array}{l}\text { Matriz de brecha d } \\
\text { Diabásio }\end{array}$ & o piroclástico \\
\hline $\begin{array}{l}\text { 目 Carbonatito } \\
\text { Rocha ultramáfica }\end{array}$ & $\begin{array}{l}\text { Granito/Aplito } \\
\text { ㅁ] Ankaratrito }\end{array}$ \\
\hline
\end{tabular}

Figura 7. Diagramas multielementares com as concentrações de elementos traços. Os dados foram normalizados pelo condrito C1 (Sun e McDonough, 1989).

deste estudo $\left(\mathrm{La} / \mathrm{Lu}_{\mathrm{nc}}=79,1 \pm 22\right)$ se comparado com as amostras de nefelina sienitos $\left(\mathrm{La} / \mathrm{Lu}_{\mathrm{nc}}=53 \pm 15\right)$, tinguaítos $\left(\mathrm{La} / \mathrm{Lu}_{\mathrm{nc}}=58,5 \pm 14\right)$ e fonólitos $\left(\mathrm{La} / \mathrm{Lu}_{\mathrm{nc}}=30 \pm 2\right)$.

No diagrama de abundância da Figura 9, observa-se padrão de enriquecimento de ETRL e ETRP em relação ao condrito $\mathrm{C} 1$ e ausência de anomalias de $\mathrm{Eu}\left(\mathrm{Eu} / \mathrm{Eu}^{*}=\right.$ $0,98 \pm 0,02)$. Os piroclastos apresentam padrão de fracionamento caracterizado pelo empobrecimento praticamente contínuo de ETRL em relação aos ETRP e pela média da razão $\mathrm{La} / \mathrm{Lu}_{\mathrm{nc}}=79,1 \pm 22$. O grau de fracionamento que ocorre no processo petrogenético pode ser avaliado pela razão da concentração normalizada do ETRL ou de ETRP (Sousa, 2017), e a razão $\mathrm{La} / \mathrm{Eu}\left(\mathrm{La} / \mathrm{Eu}_{\mathrm{nc}}=8,7 \pm 1,5\right)$ está muito próxima da razão $\mathrm{Gd} / \mathrm{Lu}\left(\mathrm{Gd} / \mathrm{Lu}_{\mathrm{nc}}=6,8 \pm 3\right)$.

As amostras de piroclastos do ponto P4 (P4.1 e P4.2) apresentam enriquecimento de $\mathrm{Ce}\left(\mathrm{Ce} / \mathrm{Ce}^{*}{ }_{\mathrm{nc}}=0,75\right.$ e 0,77 , 


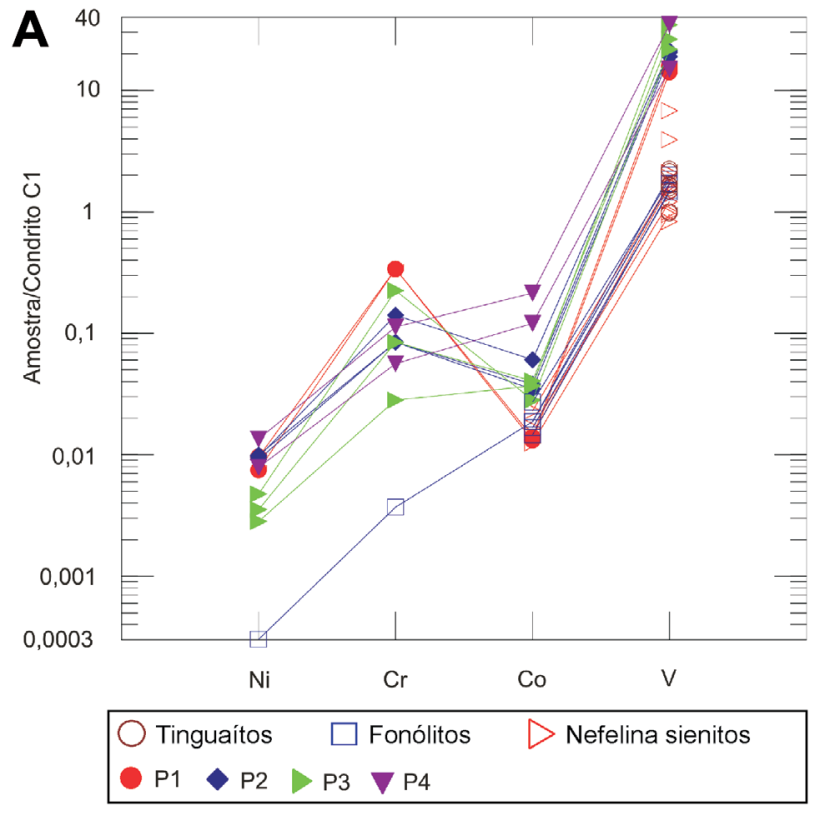

Fonólito e nefelina sienito (Schorscher e Shea, 1992) Tinguaíto e nefelina sienito (Ulbrich et al., 2005)

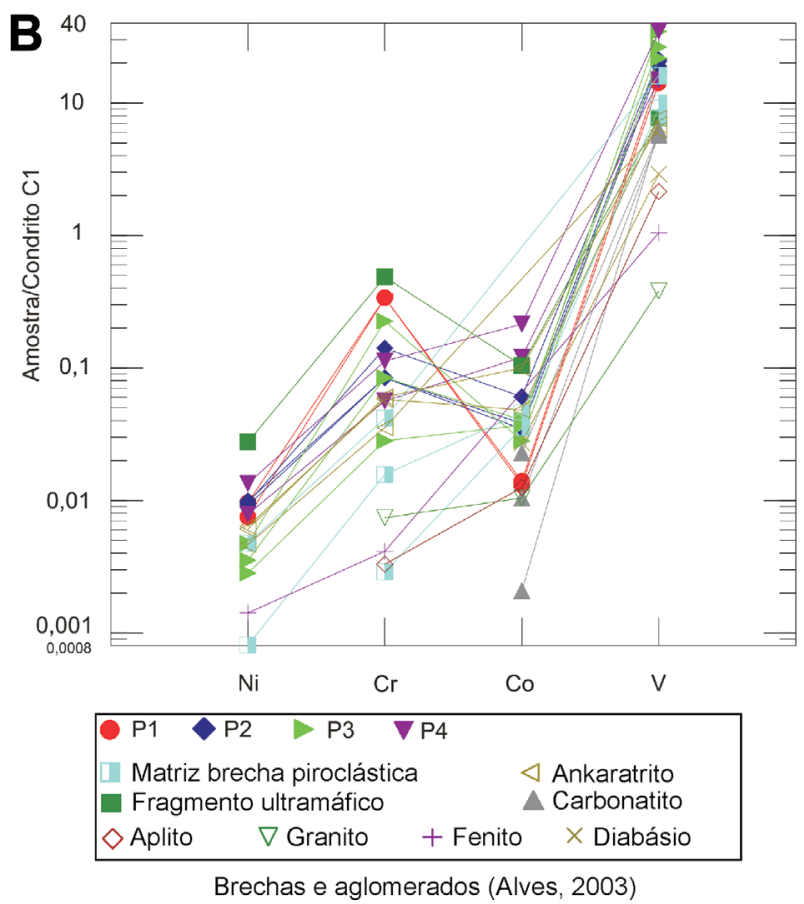

Figura 8. Diagramas multielementares com as concentrações de alguns elementos traços. Os dados foram normalizados pelo condrito C1 (Sun, 1982).

Tabela 2. Média da razão e desvio padrão das amostras de piroclastos P1, P2, P3 e P4 com as de fonólitos, nefelina sienitos e tinguaítos.

\begin{tabular}{lcccc}
\hline & $\begin{array}{c}\text { P1, P2, } \\
\text { P3 e P4 }\end{array}$ & $\begin{array}{c}\text { Nefelina } \\
\text { sienitos }\end{array}$ & Tinguaítos & Fonólitos \\
\hline $\mathrm{La} / \mathrm{Lu}_{\mathrm{nc}}$ & $79,1 \pm 22$ & $53 \pm 15$ & $58,5 \pm 14$ & $30 \pm 2$ \\
$\mathrm{La} / \mathrm{Eu}_{\mathrm{nc}}$ & $8,7 \pm 1,5$ & $33,5 \pm 12$ & $26 \pm 16,6$ & $11 \pm 2$ \\
$\mathrm{Gd} / \mathrm{Lu}_{\mathrm{nc}}$ & $6,8 \pm 3$ & $1,4 \pm 1$ & $2,16 \pm 1,3$ & $2,5 \pm 0,3$ \\
\hline
\end{tabular}

nc: normalizado pelo condrito.

Fonte: Schorscher e Shea (1992) e Ulbrich et al. (2005)

respectivamente). O ponto $\mathrm{P} 4.2$ se destaca das demais amostras pelos elevados teores em ETR $\left(\Sigma \mathrm{ETR}_{\mathrm{nc}}=17817\right)$, apesar de apresentar padrão semelhante de distribuição. Isso pode estar associado, muito provavelmente, ao estágio avançado de intemperismo do ponto amostrado (Figura 6B), que pode levar a uma concentração relativa de ETR pela lixiviação dos óxidos maiores (Figura 5).

As amostras de nefelina sienitos, fonólitos e tinguaítos (Figuras 9A, 9B e 9C e Tabela 2) também apresentam padrão de fracionamento caracterizado por um contínuo empobrecimento relativo de ETRP (nefelina sienitos $\mathrm{Gd} / \mathrm{Lu}_{\mathrm{nc}}=1,4 \pm 1$; fonólitos $-\mathrm{Gd} / \mathrm{Lu}_{\mathrm{nc}}=2,5 \pm 0,3$; e tinguaítos $-\mathrm{Gd} / \mathrm{Lu}_{\mathrm{nc}}=2,16 \pm 1,3$ ) em relação aos ETRL (nefelina sienitos $-\mathrm{La} / \mathrm{Eu}_{\mathrm{nc}}=33,5 \pm 12$; fonólitos $-\mathrm{La} / \mathrm{Eu}_{\mathrm{nc}}=11 \pm 2$; e tinguaítos $-\mathrm{La} / \mathrm{Eu}_{\mathrm{nc}}=26 \pm 16,6$ ).

A amostra P3.2 apresenta empobrecimento mais acentuado do $\mathrm{Gd}$ ao $\mathrm{Lu}\left(\mathrm{Gd} / \mathrm{Lu}_{\mathrm{nc}}=14\right)$ quando comparada às demais amostras de piroclastos (Figura 9). De forma geral, os maiores fracionamentos dos ETRP dos piroclastos em relação aos teores encontrados nos nefelina sienitos, fonólitos e tinguaítos demonstram provável atuação dos processos de intemperismo dos pontos estudados, visto que, segundo Formoso et al. (1989), a mobilidade/solubilização dos ETRP é maior que dos ETRL durante os processos intempéricos. No entanto, os padrões de fracionamento de ETR diferem dos padrões das amostras de saprólitos, bauxita e solos coletados na Caldeira Vulcânica de Poços de Caldas por Valeton et al. (1997) (Figura 9D), indicando que os piroclastos deste estudo não representam material pedogênico apesar do seu estágio de intemperização, preservando ainda assinaturas geoquímicas das rochas originais.

\section{Proveniência}

Considerando o estágio de intemperismo dos piroclastos, optou-se pelo uso dos elementos considerados de baixa mobilidade no ambiente ou de alto potencial iônico (HFSE) versus $\mathrm{Zr}$ como índice de diferenciação nos diagramas de variação (Figura 10). De forma geral, ocorre uma correlação 


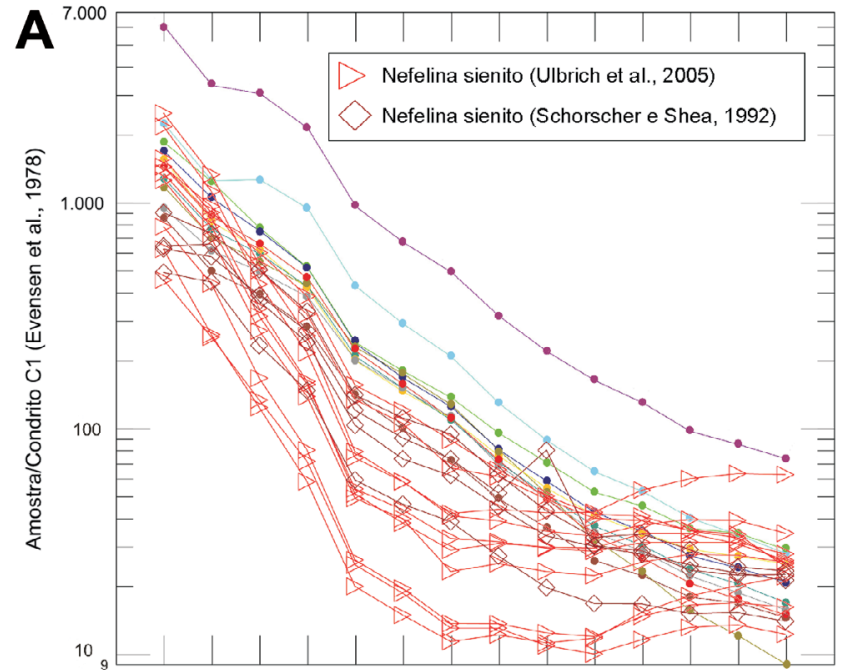

La Ce Pr Nd Sm Eu Gd Tb Dy Ho Er Tm Yb Lu

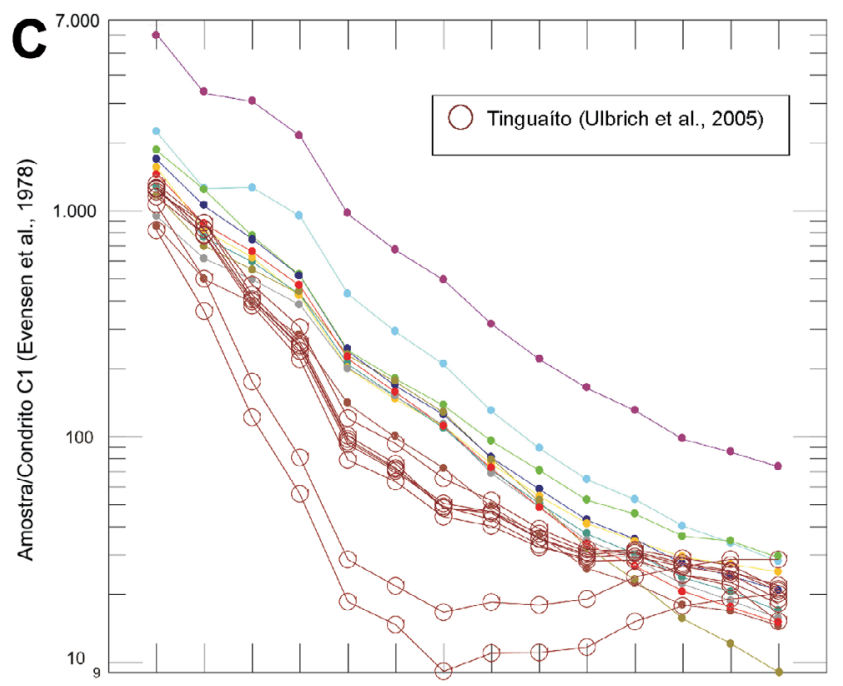

La Ce Pr Nd Sm Eu Gd Tb Dy Ho Er Tm Yb Lu

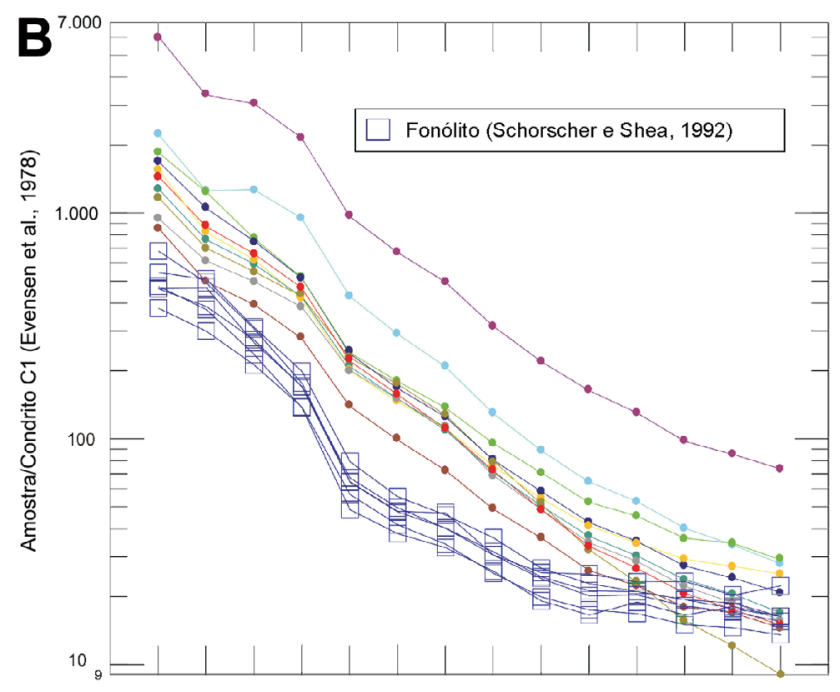

La Ce Pr Nd Sm Eu Gd Tb Dy Ho Er Tm Yb Lu

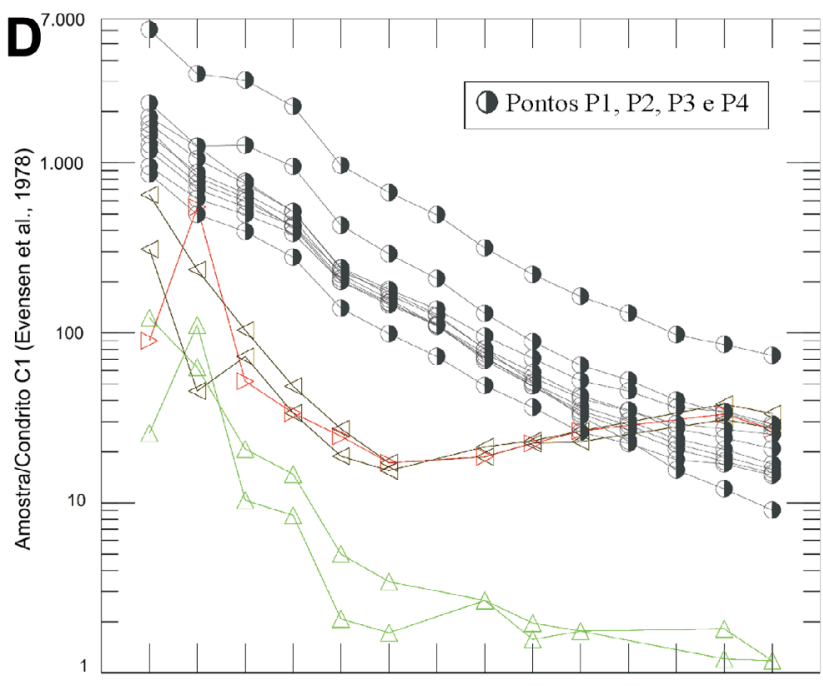

La Ce Pr Nd Sm Eu Gd Tb Dy Ho Er Tm Yb Lu

P1.1 P1.2 P2.1 P2.2 P2.3 P3.1 P3.2 P3.3 P4.1 P4.2

$\triangle$ Bauxita $\backslash$ Saprólito $>$ Solo vermelho (Valeton et al., 1997)

Figura 9. Diagramas de abundância das concentrações de elementos terras raras.

positiva entre as amostras de piroclastos, além de semelhanças principalmente nas dispersões entre Hf versus $\mathrm{Zr}$, Ce versus $\mathrm{Zr}$, La versus $\mathrm{Zr}$, Nb versus $\mathrm{Zr}$ e $\mathrm{Y}$ versus $\mathrm{Zr}$ com as amostras de nefelina sienito, tinguaíto e fonólito de Schorscher e Shea (1992) e Ulbrich et al. (2005).

Considerando a correlação positiva da Figura 10, utilizou-se o diagrama de discriminação proposto por Winchester e Floyd (1977), que utiliza a razão entre os elementos incompatíveis $\left(\mathrm{Nb} / \mathrm{Y}, \mathrm{Zr} / \mathrm{TiO}_{2}\right)$ considerados imóveis durante os processos de alteração, possibilitando, assim, distinguir o tipo de magma ou evento vulcânico que pode ter dado origem aos piroclastos deste estudo. As amostras dos piroclastos caem no campo do fonólito (Figura 11) e a utilização dos elementos incompatíveis, segundo Rollinson (1993), deve-se ao fato de que seus coeficientes de partição em massa são muito semelhantes entre si, não variando no decurso da cristalização fracionada ou variando pouco durante a fusão parcial.

Diagramas de razões contendo elementos incompatíveis têm a característica de minimizar os efeitos do fracionamento, o que permite examinar o padrão da fonte do manto (Rollinson, 1993). O diagrama de razão Th/Ta versus $\mathrm{Th} / \mathrm{Tb}$ (Figura 12A) demonstra correlação linear entre as 

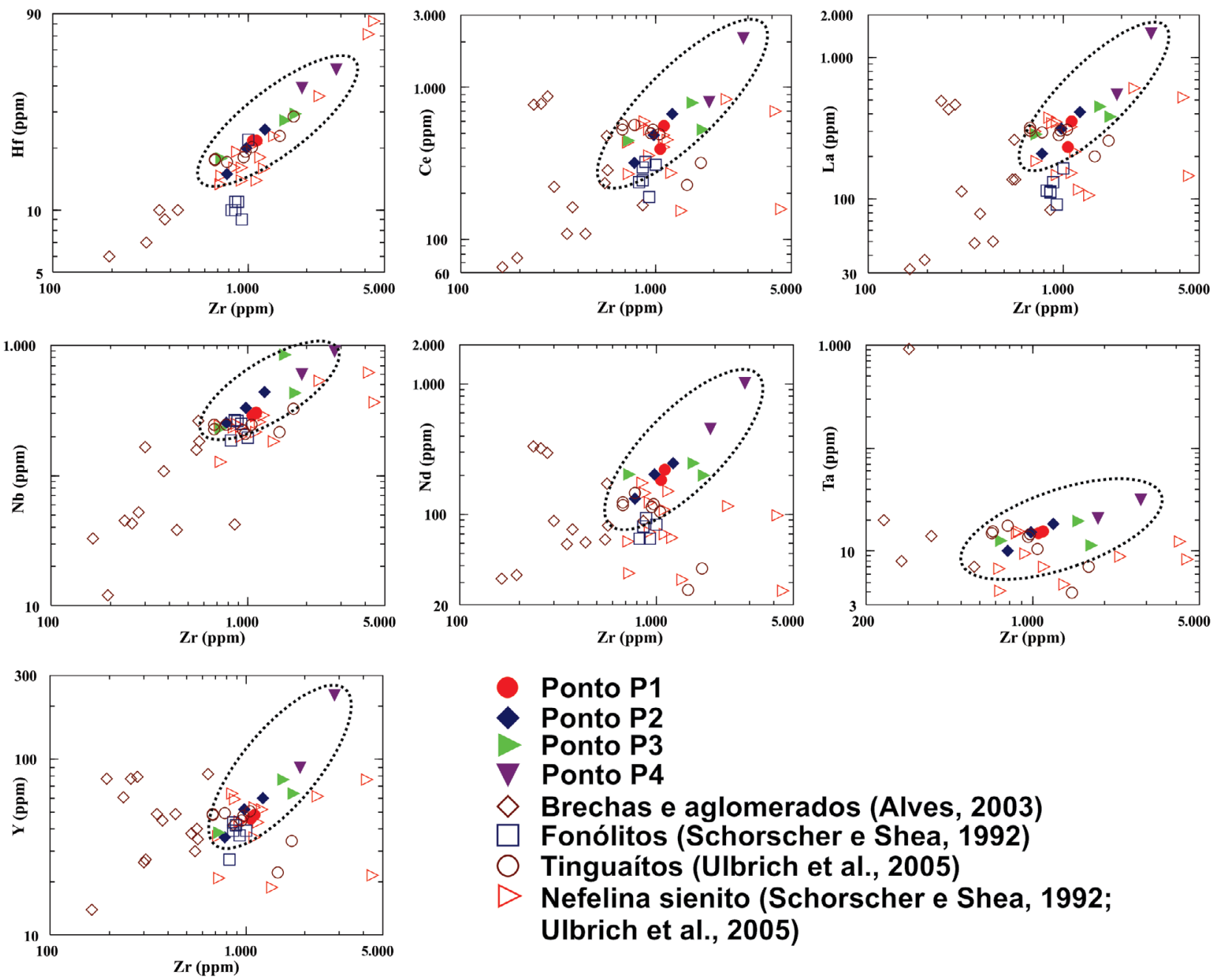

Figura 10. Diagramas de variação Zr versus elementos de baixa mobilidade no ambiente ou de alto potencial iônico (HFSE).

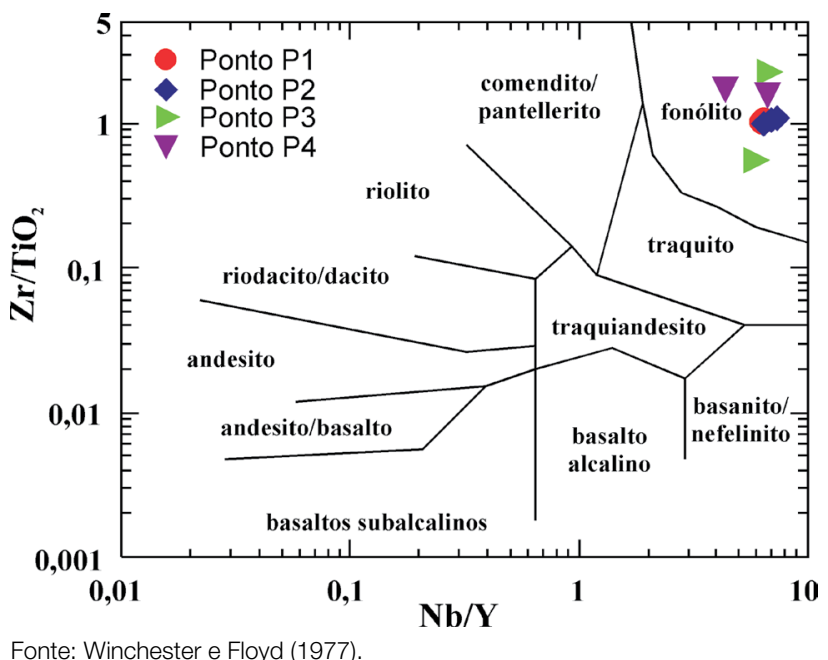

Figura 11. Diagrama de classificação de rochas ígneas. amostras dos piroclastos $\mathrm{P} 1, \mathrm{P} 2, \mathrm{P} 3$ e $\mathrm{P} 4$ com as amostras de tinguaítos e nefelina sienitos de Schorscher e Shea (1992) e Ulbrich et al. (2005), indicando provável procedência magmática comum entre elas. Se as fontes mantélicas fossem diferentes, as linhas de correlação plotariam em direções diferentes. Já o diagrama de Pearce (1982), Ce/Yb versus $\mathrm{Ta} / \mathrm{Yb}$ (Figura 12B), indica a origem alcalina, enriquecida, das amostras de piroclastos deste estudo.

Apesar da origem alcalina demonstrada nos diagramas da Figura 12, as concentrações de alguns elementos, principalmente $\mathrm{Ni}, \mathrm{Cr}$, Co e V, nos piroclastos podem sugerir provável contaminação geoquímica, oriunda de fonte magmática residual ou de materiais clásticos contidos em prováveis condutos vulcânicos que agregaram ao material piroclástico alcalino expelido e/ou presente no trajeto percorrido e que foi carreado por prováveis fluxos de lahares que posteriormente formaram os depósitos. 

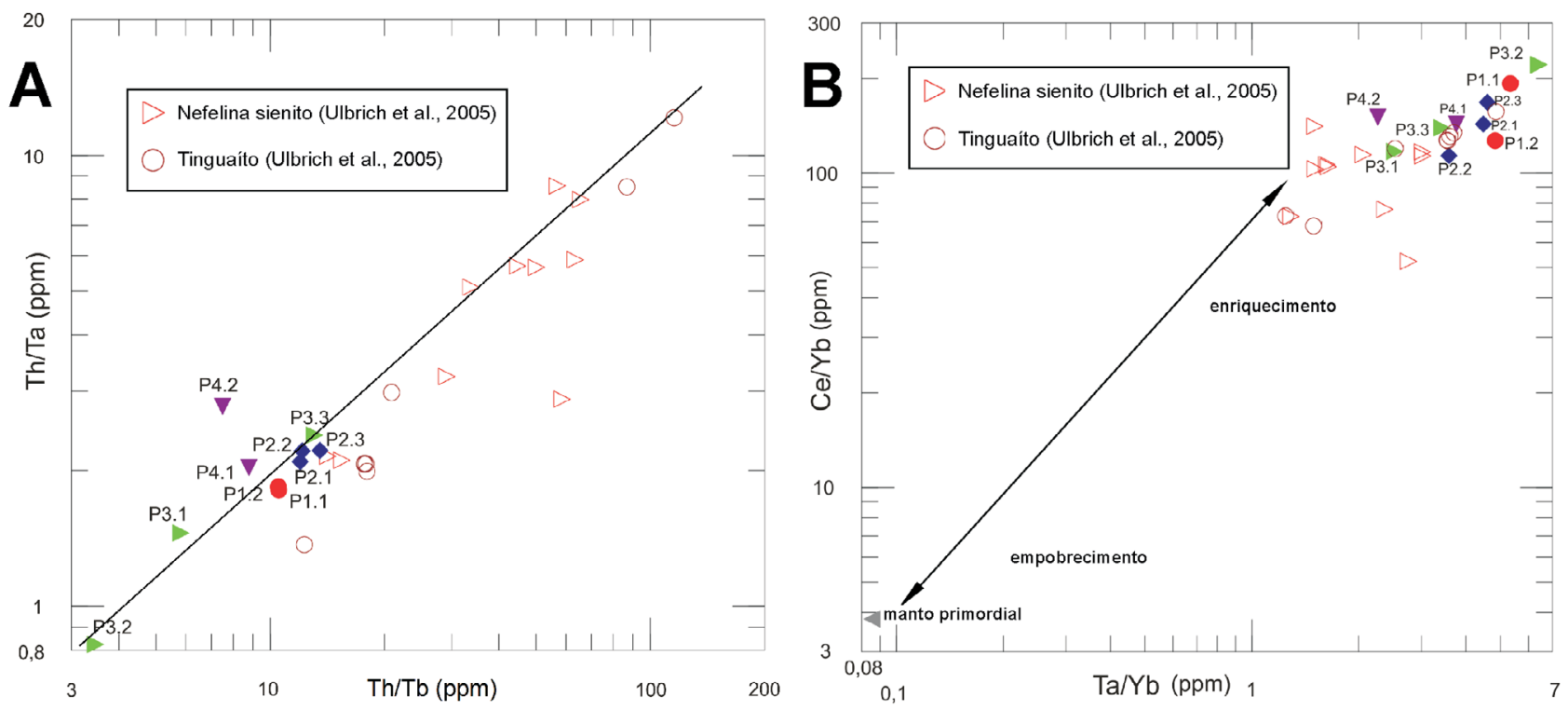

Figura 12. Diagramas binários: (A) diagrama Th/Ta versus Th/Tb indicando proveniência mantélica; (B) diagrama petrogenético $\mathrm{Ce} / \mathrm{Yb}$ versus $\mathrm{Ta} / \mathrm{Yb}$ (Pearce, 1982).

\section{CONSIDERAÇÕES FINAIS}

Segundo o modelo evolutivo proposto por Ellert (1959) e modificado por Alves (2003) para a Caldeira Vulcânica de Poços de Caldas, os depósitos piroclásticos (tufos, brechas e aglomerados vulcânicos) resultam de atividade tectônica e vulcânica ankaratrítica e deposição sobre sedimentos e embasamento pré-cambriano. Intercalações de tufos e lapilli tufo fonolíticos recobrem os ankaratritos no processo de construção do edifício vulcânico em uma fase denominada de magmatismo pré-colapso. A formação de piroclastos no magmatismo pós-colapso ocorre em um estágio de colapso de Caldeira Vulcânica, soerguimentos de blocos crustais, formação do dique anelar, intrusão de brechas de conduto vulcânico em depósitos proximais distais e superficiais e depósitos de brechas de fluxo piroclástico retrabalhadas por atividades vulcânicas mais recentes.

Com base no mecanismo de transporte (classificação genética) e considerando as feições atuais, os depósitos estudados podem ser classificados em depósito de queda de piroclastos ( $\mathrm{P} 1)$ e depósito de fluxo piroclástico $(\mathrm{P} 2$, P3 e P4). Os depósitos P2, P3 e P4 podem ter sido formados por fluxos de lahares, considerando os variados clastos polimíticos presentes na matriz de tufo saprolitizada. Com base nas feições das litofácies, foram distinguidos lapilli tufo sem estrutura (P1 e parte de P2), tufo brecha indiferenciada sem estrutura e lapilli tufo grosso (parte de P2, P3 e P4). As litofácies podem estar relacionadas com os estágios evolutivos iniciais e finais de formação da Caldeira
Vulcânica, magmatismos pré-colapso e pós-colapso, lapilli tufo, brechas em depósitos superficiais e de fluxo piroclástico retrabalhado.

A análise geoquímica dos piroclastos demonstrou baixas concentrações de $\mathrm{SiO}_{2}, \mathrm{~K}_{2} \mathrm{O}, \mathrm{Na}_{2} \mathrm{O}, \mathrm{CaO}$ e $\mathrm{MgO}$ e maiores concentrações de $\mathrm{Al}_{2} \mathrm{O}_{3}, \mathrm{Fe}_{2} \mathrm{O}_{3}$ e $\mathrm{TiO}_{2}$. Essa relação muito provavelmente se deve ao intenso processo de intemperismo, também responsável pelo enriquecimento relativo dos demais elementos. O processo avançado de intemperismo dos piroclastos pode ser analisado por meio dos diagramas de Nesbitt e Young $(1984,1989)$ e Schellmann (1994, 2003), e os resultados indicam laterização incipiente para a maioria das amostras, sendo P3.3 laterização moderada e P4.2 laterização intensa.

Os elementos traços variam pouco, havendo maior enriquecimento no ponto P4.2, de laterização intensa, ou seja, provavelmente processos de lixiviação de elementos maiores podem ter resultado no enriquecimento relativo de elementos menos móveis. Os piroclastos possuem tendência de enriquecimento na maioria dos elementos de alto potencial iônico (HFSE) e empobrecimento em elementos litófilos de grande raio iônico (LILE), como o Cs e $\mathrm{o} \mathrm{Rb}$, cujas baixas concentrações podem estar relacionadas à lixiviação/intemperismo. A exceção está no Ba que, provavelmente, substitui o K no feldspato potássico e se enriquece com a lixiviação desse elemento.

Para ETR há um padrão de fracionamento caracterizado pelo empobrecimento praticamente contínuo de ETRL em relação aos ETRP e ausência de anomalias de 
$\mathrm{Eu}$. As razões $\mathrm{La} / \mathrm{Eu}$ são próximas de $\mathrm{Gd} / \mathrm{Lu}$, além de uma incipiente anomalia de Ce no ponto P4.2, que se destaca dos demais piroclastos pelos elevados teores de ETR. Com base nos valores da média da razão dos ETR, observa-se maior fracionamento nas amostras de piroclastos em relação às amostras de rochas da Caldeira Vulcânica, especialmente em ETRP.

Quanto à proveniência, os piroclastos se situam no campo do fonólito e os resultados demonstram procedência alcalina. Além disso, a proximidade das concentrações de elementos HFSE entre as amostras estudadas e as amostras de nefelina sienitos, tinguaítos e fonólitos reforça a similaridade geoquímica desses piroclastos com as demais rochas alcalinas da Caldeira Vulcânica. No entanto, as concentrações de $\mathrm{Ni}, \mathrm{Cr}$, Co e V sugerem provável contaminação geoquímica oriunda de fonte magmática residual máfica/ultramáfica ou de materiais clásticos contidos em condutos vulcânicos e/ou presentes no trajeto percorrido por prováveis fluxos de lahares que posteriormente formaram os depósitos piroclásticos.

Apesar do maior fracionamento de ETRP e do estágio avançado de intemperismo, as amostras de piroclastos apresentam padrões de fracionamento de ETR muito diferentes das amostras de saprólitos, bauxita e solos de Caldeira Vulcânica, que conferem aos perfis características não pedogênicas, indicando que esses depósitos ainda preservam as propriedades de assinatura geoquímica do magma primordial. Além disso, os resultados apresentados estão de acordo com o modelo evolutivo de caldeira vulcânica, corroborando com a hipótese proposta por Ellert (1959) e revisada por Alves (2003) para Poços de Caldas.

\section{AGRADECIMENTOS}

Os autores agradecem aos revisores anônimos que contribuíram para a melhora deste manuscrito. Além disso, a pesquisa não foi financiada nem fomentada por nenhum órgão ou instituição, e sim por esforços pessoais dos autores.

\section{REFERÊNCIAS}

Almeida, F. F. M., Carneiro, C. D. R. (2012). Corpos alcalinos de Poços de Caldas, Itatiaia e São Sebastião. In: Y. Hasui, C. D. R. Carneiro, F. F. M. Almeida, A. Bartorelli. Geologia do Brasil, 464-466. São Paulo: Beca.

Alves, A. D. (2003). Rochas Vulcanoclásticas do Complexo Alcalino de Poços de Caldas - MG/SP. Dissertação (Mestrado). São Paulo: Instituto de Geociências, USP. https://doi.org/10.11606/D.44.2003.tde-02042014-104025
Augustin, C. H. R. R., Lopes, M. R. S., Silva, S. M. (2013). Lateritas: um conceito ainda em construção. Revista Brasileira de Geomorfologia, 14(3), 241-257. http://dx.doi.org/10.20502/ rbg.v14i3.202

Chapman, N. A., McKinley, I. G., Shea, M. E., Smellie, J. A. T. (1991). The Poços de Caldas Project: Summary and Implications for Radioactive Waste Management. SKBTechnical Report, 90-24 (Swedish Nuclear Fuel and Waste Management Co.). Disponível em: $<$ https://www.skb.com/ publication/7708/TR90-24_inlaga.pdf $>$. Acesso em: 18 ago. 2020.

Companhia de Desenvolvimento Econômico de Minas Gerais (CODEMIG). (2015). Projeto Fronteiras de Minas Gerais - Folha Caldas/Poços de Caldas. Escala 1:100.000. Belo Horizonte: Companhia de Desenvolvimento Econômico de Minas Gerais.

Departamento Nacional de Produção Mineral (CPRM). (1979). Projeto Sapucaí: relatório final. Escala 1:250.000. Companhia de Pesquisa de Recursos Minerais. São Paulo: Editora do Departamento Nacional de Produção Mineral.

Ellert, R. (1959). Contribuição à geologia do maciço alcalino de Poços de Caldas. Boletim Faculdade de Filosofia, Ciências e Letras USP, (18), 5-60. https://doi.org/10.11606/issn.25263862.bffcluspgeologia.1959.121851

Evensen, N. M., Hamilton, P. J., O'nions, R. K. (1978). Rare-earth abundances in chondritic meteorites. Geochimica et Cosmochimica Acta, 42(8), 1199-1212. https://doi. org/10.1016/0016-7037(78)90114-X

Fisher, R. V. (1960). Classification of Volcanic Breccias. Bulletin of the Geological Society of America, 71(7), 973-982. https:// doi.org/10.1130/0016-7606(1960)71[973:COVB]2.0.CO;2

Fisher, R. V., Heiken, G., Mazzoni, M. (2006). Where do tuffs fit into the framework of volcanoes? In: G. Heiken. Tuffs: Their Properties, Uses, Hydrology, and Resources. Boulder: The Geological Society of America, v. 408. https:// doi.org/10.1130/2006.2408(2.1)

Formoso, M. L. L., Nardi, L. V. S., Hartman, L. A. (1989). Geoquímica dos elementos terras raras no Brasil. Brasil: CPRM/DNPM, Sociedade Brasileira de Geoquímica.

Garda, M. G. (1990). A alteração hidrotermal no contexto da evolução geológica do maciço alcalino de Poços de Caldas, $M G$-SP. Dissertação (Mestrado). São Paulo: Instituto de Geociências, USP. https://doi.org/10.11606/D.44.1990. tde-02092013-144159 
Green, T. H. (1980). Island Arc and Continent-Building Magmatism - A review of petrogenic models based on experimental petrology and geochemistry. Tectonophysics, 63(1-4),367-385. https://doi.org/10.1016/0040-1951(80)90121-3

Holmes, D. C., Pitty, A. E., Noy, D. J. (1992). Geomorphological and hydrogeological features of the Poços de Caldas caldera analogue study sites. Journal of Geochemical Exploration, 45(1-3), 215-247. https://doi. org/10.1016/0375-6742(92)90126-S

Huber, H., Koeberl, C., Egger, H. (2003). Geochemical study of lower Eocene volcanic ash layers from the Alpine Anthering Formation, Austria. Geochemical Journal, 37(1), 123-134. https://doi.org/10.2343/geochemj.37.123

Indústrias Nucleares do Brasil (INB). (2011). Programa de Recuperação de Áreas Degradadas (PRAD). UTM - Caldas - Minas Gerais. No Projeto099-515-3023. Mapa Geológico Regional (2). Escala 1:150.000. Rio de Janeiro: Indústrias Nucleares do Brasil.

Instituto Brasileiro de Geografia e Estatística (IBGE). (1972). Carta de Poços de Caldas. Folha SP-23-V-C-VI-4. Escala 1:50.000. Brasília: Instituto Brasileiro de Geografia e Estatística. Superintendência de Cartografia.

Jerram, D., Petford, N. (2014). Descrição de Rochas Ígneas - Guia Geológico de Campo. $2^{\mathrm{a}}$ ed. Tradução: Ana Maria Pimentel Mizusaki, Rualdo Menegat. Porto Alegre: Bookman.

Mason, B. H. (1971). Princípios de Geoquímica. Tradução: Rui Ribeiro Franco. São Paulo: Polígono Editora da USP.

McClintock, M., White, J. D. L. (2006). Large phreatomagmatic vent complex at Coombs Hills, Antarctica: Wet, explosive initiation of flood basalt volcanism in the Ferrar-Karoo LIP. Bulletin of Volcanology, 68(3), 215-239. https://doi. org/10.1007/s00445-005-0001-1

Motoki, A., Oliveira, J. L. S. (1987). Reconsiderações vulcanológicas sobre a hipótese de caldeira vulcânica no Complexo Alcalino de Poços de Caldas, MG. Parte I: Rochas sedimentares como corpos capturados, fragmentados e afundados no magma fonolítico. IV Simpósio de Geologia de Minas Gerais, 240-243.

Motoki, A., Sichel, S. E. (2006). Avaliação de aspectos texturais e estruturais de corpos vulcânicos e subvulcânicos e sua relação com o ambiente de cristalização, com base em exemplos do Brasil, Argentina e Chile. Ouro Preto, REM: Revista Escola de Minas, 59(1), 13-23. https://doi. org/10.1590/S0370-44672006000100003
Motoki, A., Sichel, S. E., Soares, R., Aires, J. R., Savi, D. C., Petrakis, G. H., Motoki, K. F. (2008). Rochas piroclásticas de preenchimento de condutos subvulcânicos do Mendanha, Itaúna e Ilha do Cabo Frio, RJ, e seu processo de formação com base no modelo de implosão de conduto. Geociências, 27(4), 451-467.

Muhs, D. R., Budahn, J. R. (2009). Geochemical evidence for African dust and volcanic ash inputs to terra rossa soils on carbonate reef terraces, northern Jamaica, West Indies. Quaternary International, 196(1-2), 13-35. https://doi. $\operatorname{org} / 10.1016 / j$.quaint.2007.10.026

Nesbitt, H. W., Young, G. M. (1984). Prediction of some weathering trends of plutonic and volcanic rocks based on thermodynamic and kinetic considerations. Geochimica et Cosmochimica Acta, 48(7), 1523-1534. http://dx.doi. org/10.1016/0016-7037(84)90408-3

Nesbitt, H. W., Young, G. M. (1989). Formation and Diagenesis of Weathering Profiles. Journal of Geology, 97(2), 129-147. https://doi.org/10.1086/629290

Pearce, J. A. (1982). Trace element characteristics of lavas from destructive plate boudaries. In: R. S. Thorpe (Ed.). Andesites: Orogenic Andesites and Related Rocks, v. 1, 525-548. Chichester: Wiley \& Sons.

Rollinson, H. (1993). Using Geochemical data: evaluation, presentation, interpretation. Londres: Longman Group. https://doi.org/10.4324/9781315845548

Ruggieri, F., Saavedra, J., Fernandez-Turiel, J. L., Gimeno, D., Garcia-Valles, M. (2010). Environmental geochemistry of ancient volcanic ashes. Journal of Hazardous Materials, 183(1-3), 353-365. https://doi.org/10.1016/j. jhazmat.2010.07.032

Schellmann, W. (1994). Geochemical differentiation in laterite and bauxite formation. Catena, 21(2-3), 131-143. https://doi.org/10.1016/0341-8162(94)90007-8

Schellmann, W. (2003). Discussion of A critique of the Schellmann definition and classification of laterite by R. P. Bourman and C. D. Ollier (Catena 47, 117131). Catena, 52(1), 77-79. https://doi.org/10.1016/ S0341-8162(02)00178-9

Schorscher, H. D., Shea, M. E. (1992). The regional geology of the Poços de Caldas alkaline complex: mineralogy and geochemistry of selected nepheline syenites and phonolites. Journal of Geochemical Exploration, 45(1-3), 25-51. https:// doi.org/10.1016/0375-6742(92)90121-n 
Sommer, C. A., Lima, E. F., Nardi, L. V. S., Liz, J. D., Pierosan, R. (2003). Depósitos de Fluxo Piroclástico Primários: Caracterização e Estudo de um Caso no Vulcanismo Ácido Neoproterozóico do Escudo Sul-riograndense. Pesquisa em Geociências, 30(1), 3-26. https:// doi.org/10.22456/1807-9806.19576

Sousa, T. A. (2017). Elementos terras raras como indicadores do aporte e proveniência sedimentar nos últimos 45 mil anos, Bacia de Santos - Brasil. Dissertação (Mestrado). Niterói: Universidade Federal Fluminense. Disponível em: $<\mathrm{https}: / /$ app.uff.br/riuff/handle/1/3269>. Acesso em: 18 ago. 2020.

Sun, S. S. (1982). Chemical composition and origin of the earth's primitive mantle. Geochimica et Cosmochimica Acta, 46(2), 179-192. https://doi.org/10.1016/0016-7037(82)90245-9

Sun, S. S., McDonough, W. F. (1989). Chemical and isotopic systematics of oceanic basalts: implications for mantle composition and processes. Geological Society, Special Publications, 42(1), 313-345. https://doi.org/10.1144/GSL. SP.1989.042.01.19

Tucker, M. E. (2014). Rochas Sedimentares - Guia Geológico de Campo. $4^{\mathrm{a}}$ ed. Tradução: Rualdo Menegat. Porto Alegre: Bookman.

Ulbrich, H. H. G. J., Vlach, S. R. F., Demaiffe, D., Ulbrich, M. N. C. (2005). Structure and origin of the Poços de Caldas
Alkaline Massif, SE Brazil. In: P. Comin-Chiaramonti, C. B. Gomes (Eds.). Mesozoic to Cenozoic Alkaline Magmatism in the Brazilian Platform, 367-418. São Paulo: Editora da Universidade de São Paulo, 889 p.

Ulbrich, H. H. G. J., Vlach, S. R. F., Ulbrich, M. N. C., Kawashita, K. (2002). Penecontemporaneous syenitic-phonolitic and basic-ultrabasic-carbonatitic rocks at the Poços de Caldas alkaline massif, SE Brazil: geologic and geochronologic evidence. Revista Brasileira de Geociências, 32(1), 15-26. https://doi.org/10.25249/0375-7536.20023211526

Valeton, I., Schumann, A., Vinx, R., Wieneke, M. (1997). Supergene alteration since the upper cretaceous on alkaline igneous and metasomatic rocks of the Poços de Caldas ring complex, Minas Gerais, Brazil. Applied Geochemistry, 12(2), 133-154. https://doi.org/10.1016/S0883-2927(96)00060-1

Winchester, J. A., Floyd, P. A. (1977). Geochemical discrimination of different magma series and their differentiation products using immobile elements. Chemical Geology, 20, 325-343. https://doi.org/10.1016/0009-2541(77)90057-2

Zhou, Y., Bohor, B. F., Ren, Y. (2000). Trace element geochemistry of altered volcanic ash layers (tonsteins) in Late Permian coal-bearing formations of eastern Yunnan and western Guizhou Provinces, China. International Journal of Coal Geology, 44(3-4), 305-324. https://doi.org/10.1016/ S0166-5162(00)00017-3 